\title{
Ghost-house busters: the electoral response to a large anti-tax evasion program
}

\author{
Casaburi, Lorenzo ; Troiano, Ugo
}

\begin{abstract}
The incentives of political agents to enforce tax collection are key determinants of the levels of compliance. We study the electoral response to the Ghost Buildings program, a nationwide anti tax evasion policy in Italy that used innovative monitoring technologies to target buildings hidden from tax authorities. The program induced monetary and non-monetary benefits for non-evaders and an increase in local government expenditures. A one standard deviation increase in town-level program intensity leads to a $4.8 \%$ increase in local incumbent reelection rates. In addition, these political returns are higher in areas with lower tax evasion tolerance and with higher efficiency of public good provision, implying complementarity among enforcement policies, the underlying tax culture, and the quality of the government.
\end{abstract}

DOI: https://doi.org/10.1093/qje/qjv041

Posted at the Zurich Open Repository and Archive, University of Zurich ZORA URL: https://doi.org/10.5167/uzh-127519

Journal Article

Accepted Version

Originally published at:

Casaburi, Lorenzo; Troiano, Ugo (2016). Ghost-house busters: the electoral response to a large anti-tax evasion program. Quarterly Journal of Economics, 131(1):273-314.

DOI: https://doi.org/10.1093/qje/qjv041 


\title{
GHOST-HOUSE BUSTERS: THE ELECTORAL RESPONSE TO A LARGE ANTI TAX EVASION PROGRAM*

\author{
Lorenzo Casaburi Ugo Troiano
}

This Version: August 2015

\begin{abstract}
The incentives of political agents to enforce tax collection are key determinants of the levels of compliance. We study the electoral response to the Ghost Buildings program, a nationwide anti tax evasion policy in Italy that used innovative monitoring technologies to target buildings hidden from tax authorities. The program induced monetary and non-monetary benefits for non-evaders and an increase in local government expenditures. A one standard deviation increase in town-level program intensity leads to a 4.8 percent increase in local incumbent reelection rates. In addition, these political returns are higher in areas with lower tax evasion tolerance and with higher efficiency of public good provision, implying complementarity among enforcement policies, the underlying tax culture, and the quality of the government.
\end{abstract}

JEL codes: H26, H71, D72, E62, O17, O38

* Lorenzo Casaburi, casaburi@stanford.edu. Ugo Troiano, troiano@umich.edu. We are indebted to the Agenzia del Territorio that provided the administrative data used in this paper. We thank the Editor (Elhanan Helpman), the Coeditor (Andrei Shleifer), and four anonymous referees for suggestions that improved the paper significantly. We also wish to thank Alberto Alesina, Joseph Altonji, Josh Angrist, Sam Asher, Robert Barro, Raj Chetty, David Cutler, Pascaline Dupas, Ed Glaeser, Jim Hines, Larry Katz, Michael Kremer, Asim Kwhaja, Jacob Leshno, Massimo Maoret, Sendhil Mullainathan, Aurelie Ouss, Manisha Padi, Rohini Pande, Torsten Persson, Dina Pomeranz, Adam Ray, Tristan Reed, Giovanni Reina, László Sándor, Monica Singhal, Joel Slemrod, Andrea Stella, Seth Stephens-Davidowitz, David Strömberg, Tavneet Suri, David Yanagizawa-Drott, and seminar audiences at Berkeley, Boston University, EEA Meetings, Harvard, MIT, NTA Meetings, RES Meetings, Stanford, and the University of Michigan. Traviss Cassidy and Morris Hamilton provided excellent research assistance. All errors are our own. 


\section{Introduction}

A government's ability to enforce tax collection efficiently is one of the fundamental components of state capacity and, in turn, has historically been an important driver of economic development. Tax evasion generates significant losses and distortions in government revenues. ${ }^{1}$ The literature (e.g., Slemrod [2007]; Besley and Persson [2013]) describes three main determinants of tax compliance: enforcement technology, political incentives, and cultural norms. This paper illustrates the interaction among these three factors. We estimate the electoral returns - the change in reelection likelihood - that local policymakers obtain from a nationwide anti-evasion policy in Italy based on an innovation in tax compliance monitoring technology. In addition, we study how these electoral returns depend on underlying social preferences for tax compliance and on local government efficiency in the provision of public goods. To the best of our knowledge, this paper provides the first empirical evidence concerning voters' responses to anti-evasion policies.

Measures to reduce tax evasion generate a conflict between voters. The measures hurt tax evaders, typically a minority of voters, while the majority of the population is likely to benefit from additional government expenditures, lower tax rates, or even directly from the punishment of former shirkers. For instance, a recent survey administered by Bank of Italy finds that approximately 76 percent of the respondents believed that fighting tax evasion should be among the foremost priorities for Italian public policy [Cannari and D'Alessio, 2007]. However, the magnitude of the individual costs tax evaders incur from enforcement is potentially higher than the individual benefit non-evaders derive from it. Anti-evasion policies are thus canonical examples of policies that are asymmetric in their concentration of costs and benefits [Tullock, 1959; Olson, 1965]. Due to this asymmetry, fighting tax evasion may either benefit or harm politicians who seek reelection. The sign of this impact is ex ante ambiguous and, therefore, an empirical question.

In 2007, the Italian government instituted a nationwide anti-evasion policy, the Ghost Buildings program. The program identified ghost buildings - properties not included in the land registry and thus hidden from tax authorities - by overlaying aerial photographs and digital land registry maps. The intervention detected more than two million parcels

\footnotetext{
${ }^{1}$ Slemrod [2007] states that, according to existing evidence: "the overall net noncompliance rate for all U.S. federal taxes and the individual income tax seems to stand at about 14 percent". Estimates from other developed countries deliver similar figures (for Italy, see Marino and Zizza [2012]). In developing countries, where the share of the informal economy is typically larger, the figures are much higher [Gordon and Li, 2009]. La Porta and Shleifer [2008] focus on the relationship between economic development and the size of the informal economy.
} 
(the unit of the land registry) with ghost buildings. ${ }^{2}$ A large registration program targeting the identified ghost buildings followed the completion of the mapping exercise. The central government began the program and coordinated registration activities. Municipal administrations circulated information about the program, collaborated with follow-up inspections, and enforced payment of overdue local taxes. Media reports highlight both the importance of local administrations in the registration process and that local governments took credit for the enforcement that followed the mapping exercise.

The program led to a substantial wave of building registrations. Administrative data reveal that around 40 percent of the ghost buildings were registered by the end of 2011 . Total tax revenues increased by 472 million euros in that year as a result of the program, with a large share of these extra revenues coming from local (i.e. town) taxes. The intensity of the additional tax enforcement varied significantly across towns. In towns with a higher prevalence of detected ghost buildings, the program was more likely to affect the amount of building registration. We use a measure of Ghost Building Intensity, the ratio of the number of land registry parcels with ghost buildings identified by the program to the total number of land registry parcels in the town, to proxy for the scope of the program. Ceteris paribus, there is a higher opportunity to reduce tax evasion in towns with a larger fraction of ghost buildings detected by the program.

The data show that the increase in enforcement is stronger in towns with higher ghost building intensity. Using a difference-in-differences approach, we test the impact of the antievasion policy on the reelection of local incumbents by exploiting the cross-municipality variation in this intensity. Our strategy controls for time-invariant town characteristics through the use of town fixed effects. It identifies the causal effect of the policy scope to increase enforcement on electoral outcomes under standard assumptions that we verify in the data. The results show sizable political responses. In local elections occurring after the beginning of the program, an increase of one standard deviation in the ghost building intensity raises the likelihood of reelection of the local incumbent relative to pre-program elections by approximately 2.2 percentage points, approximately 4.8 percent of the average reelection rate (45.4 percent). Higher town-level ghost building intensity also lowers several measures of competitiveness in local elections. In particular, it reduces the number of candidates running for election, increases the margin of victory for the winner, and reduces the likelihood of a runoff.

\footnotetext{
${ }^{2}$ Parcels are defined at the town level. According to the legal definition (Reggio Decreto n.1952, 1931), they can vary in size, but they capture portions of land (or buildings) that belong to the same owner, are of similar quality, and have the same usage.
} 
Guiding our empirical models are several retrospective voting frameworks of political agency [Barro, 1973; Ferejohn, 1986; Besley, 2007], which we adapt to study tax evasion. Through these frameworks, we identify the mechanisms that can induce a change in voter choices following a change in tax enforcement. Additional analysis of the actual building registrations induced by the program complements the reduced-form analysis described above. For a given town-level program scope, a higher registration rate of ghost buildings has a positive effect on the likelihood of reelection of the incumbent during the program.

We provide evidence for two channels that could drive the observed electoral response. First, using survey data on the self-reported tolerance for tax evasion among voters, we show that the program positive impact on incumbent reelection is significantly higher in areas with lower tolerance for tax evasion. Second, towns where the government is more efficient in delivering public goods show a larger electoral response to the program. We also verify that towns with higher ghost building intensity experienced a differential increase in local government expenditures following the program inception. Finally, we discuss potential alternative interpretations of the impact of the program on the incumbent's reelection. In the first, the program changes voter behavior by providing information on the existing stock of ghost buildings. In the second, it gives the incumbent an electoral rent by giving her the option to not register identified ghost buildings. In the third, it changes the likelihood that the incumbent mayor is elected to a higher level position. We use our results and features of the institutional setting to show that these competing explanations cannot drive the results.

Our approach can be applied to different settings to study the political feasibility of upgrading tax administrations around the world using new electronic data, cross-checking technologies, and other monitoring devices [Bird and Zolt, 2008]. ${ }^{3}$ Additionally, our analysis points at a complementarity between technological innovations in tax enforcement and political incentives. When exposed to a reduction in monitoring costs, politicians can exploit the new technologies and experience political gains. Additionally, our study provides evidence that the underlying tax culture shapes the political incentives for tax enforcement and the political returns to these innovations [Torgler, 2007; Rothstein, 2000].

Finally, access to the program town-level nationwide administrative data allows us to provide evidence on two additional fronts. First, we study the correlates of tax evasion at the town level. We find that geographical features such as town size are important determinants of tax evasion, consistent with Saiz [2010], and that social capital is negatively correlated with tax evasion [Putnam, 2001]. Second, we document that mayors' characteristics, such as

\footnotetext{
${ }^{3}$ For instance, other countries, such as Greece and Rwanda, have recently implemented policies using similar technologies.
} 
education, gender, and age, affect the extent to which the Ghost Buildings program increased tax enforcement (consistent with Alesina [1988], Besley and Coate [1997], Besley, Montalvo and Reynal-Querol [2011]).

This paper relates to several strands of literature. First, a recent set of studies uses microdata to shed light on enforcement technologies such as third-party reporting [Slemrod, Blumenthal, and Christian, 2001; Saez, 2010; Kleven et al., 2011; Chetty, Friedman, and Saez, 2013; Naritomi, 2015], paper trails [Kumler, Verhoogen, and Frías, 2011; Pomeranz, forthcoming], cross-checking [Carrillo, Pomeranz, and Singhal, 2014], targeted auditing strategies [Almunia and Lopez-Rodriguez, 2014; Aparicio, 2012] and third-party monitoring of customs duty collection [Yang, 2008a, 2008b]. ${ }^{4}$ Second, this paper is related to the political agency literature [Barro, 1973; Ferejohn, 1986; Besley, 2007]. Retrospective voting models have received considerable empirical support, for example in the context of fiscal stabilization [Brender, 2003; Brender and Drazen, 2008; Alesina, Carloni, and Lecce, 2012].

By studying how technology-driven enforcement policies affect policymakers, we build a bridge between the political agency and the tax evasion literature. In addition, by delving into the relationship between the incentives of political agents and tax evasion, our paper is related to the work of Artavanis, Morse, and Tsoutsoura [2012], who find that tax evasion is higher in industries supported by parliamentarians. Finally, our results provide support to existing literature that highlights the roles of culture and social norms as determinants of tax evasion, either via cross-country analysis [Torgler, 2003; Slemrod, 2003], lab experiments [Spicer and Becker, 1980; Alm, Jackson, and McKee, 1992] or field experiments [Hallsworth et al., 2014; Luttmer and Singhal, 2014].

The remainder of the paper is organized as follows. Section 2 describes the Ghost Buildings program. Section 3 presents several conceptual frameworks that rationalize the impact of a change in tax enforcement on voters' electoral choices. Section 4 describes the data and presents descriptive evidence. Section 5 lays out our empirical strategy to estimate the electoral response to the policy. Section 6 presents the results. Section 7 concludes.

\section{The Ghost Buildings Program}

The value of the buildings registered in the land registry enters the tax base for several national and local taxes, including ICI/IMU (the local property tax), IRPEF (the personal income tax, which is both national and local), and the local waste management tax. Italian

\footnotetext{
${ }^{4}$ For a review of the literature, see Andreoni, Erard, and Feinstein [1998] and Slemrod and Yitzhaki [2002].
} 
legislation requires owners to register new buildings at the local office of the Agenzia del Territorio, the agency managing the land registry, within thirty days after their completion. ${ }^{5}$

In 2006, the national government approved new anti-evasion legislation, authorizing the beginning of the Ghost Buildings program for the following year. The program was aimed at detecting buildings not registered on the land registry maps. ${ }^{6}$ Italy's national politics were unstable during the years in which the program was implemented: Silvio Berlusconi (rightwing) was the Prime Minister in the first half of 2006, Romano Prodi (left-wing) was the Prime Minister from the second half of 2006 to 2008, and Silvio Berlusconi was again Prime Minister between 2008 and 2011. Therefore, the attribution of the policy to one specific national party is not obvious.

The Agenzia del Territorio coordinated the effort. The agency first juxtaposed the land and building registry maps to obtain the Official Building Map. It subsequently compiled high-resolution $(50 \mathrm{~cm})$ aerial photographs of the entire country to identify the ghost buildings. Appendix Figures A.1A-A.1C summarize the identification steps. First, the aerial photograph of a particular location was created. Then, the pictures were matched to the official building map for the corresponding area. Finally, the ghost buildings were identified. ${ }^{7}$ Ghost buildings include commercial, industrial, and residential stand-alone buildings, as well as substantial extensions of previously registered buildings that should have been reported to the land registry.

Through this process, the Agenzia del Territorio identified approximately two million land registry parcels containing unregistered buildings. Beginning in August 2007, the Agenzia del Territorio started publishing parcel-level data on unregistered properties in the Gazzetta Ufficiale, the official bulletin promulgating Italian laws and decrees, to induce registrations of the ghost buildings. Within three years, it coded detailed information on the number of ghost buildings in the universe of Italian municipalities targeted by the program. The order of publication relied on the availability of digitized land registry maps at the time when the

\footnotetext{
${ }^{5}$ See Legge 9 Marzo 2006 n.80 - Art. 34-quinquies. All buildings in Italy require a building permit before construction can begin, and obtaining a building permit makes the new building part of the City Plan. The process of obtaining building permits is administered independently from the registration in the land registry maps. Buildings that are not in the City Plan are required to be demolished.

${ }^{6}$ See Legge 24 novembre 2006, $n$. 286 subsequently modified by Legge 30 Luglio 2010, $n$. 122. The detection exercise did not cover one of the semi-autonomous regions, Trentino Alto-Adige, because land registry maps are autonomously administered in that region. The region contains less than two percent of the total population of Italy.

${ }^{7}$ According to the Law Decreto Ministero delle Finanze 2 gennaio 1998, n.28.Art. 3, the following buildings do not constitute part of the statutory tax base of their owners and thus are not subject to registration requirements: (i) buildings that are incomplete; (ii) buildings that are particularly degraded; (iii) solar collectors; (iv) greenhouses; and (v) henhouses or other buildings reserved for animals.
} 
program started. ${ }^{8}$ The Agenzia del Territorio had 60 percent of the land registry maps of the Italian territory in digitized form before the Ghost Buildings program was approved. After 2006, the Agenzia del Territorio began digitizing the remaining land registry maps, proceeding by province (i.e., they simultaneously coded different municipalities in the same province). It completed the identification exercise by the end of $2010 .^{9}$

According to the initial legislation, owners could register the detected ghost building with the land registry by April 30, 2011. ${ }^{10}$ Widespread media campaigns and local administrations' efforts contributed to achieve high registration rates. In particular, local administrators a) disseminated information about targeted parcels; b) collaborated on follow-up building inspections; c) proceeded with the collection of overdue local taxes up to five years before the program began; and d) verified the conformity of ghost buildings to the city plan and local zoning restrictions. ${ }^{11}$ In addition, there is extensive evidence from the media that local governments often attempted to take credit for the registration process [Langellotti, 2014]. In Section 3, we highlight this is an important element for understanding the voter responses we document in this paper.

Owners of ghost buildings who registered prior to the April 2011 deadline were required to pay overdue taxes dating back to 2007, or to the construction date for post-2007 cases, and to pay penalties for delayed payments. After April 2011, the Agenzia del Territorio, with the support of local administrations and contractors, proceeded with follow-up inspections to impute the tax base for the remaining unregistered buildings. ${ }^{12}$ Additional penalties and a fee for the extra inspection were charged to the owners of buildings for which the Agenzia del Territorio imputed the tax base after April 2011. In Section 4, we describe the impact of the program on the level of tax evasion.

\footnotetext{
${ }^{8}$ The identity of the owners of the unregistered buildings was not revealed and the program did not have a shaming component associated to it. For the effect of shaming on tax compliance see Perez-Truglia and Troiano [2015].

${ }^{9}$ Publication in the Gazzetta Ufficiale occurred in the following waves: August 2007, October 2007, December 2007, December 2008, December 2009, December 2010.

${ }^{10}$ This was after extending on two previous deadlines of ninety days and seven months since the publication in the Gazzetta Ufficiale, respectively.

${ }^{11}$ Registration in the land registry does not imply that the building is waived from zoning restrictions.

${ }^{12}$ To further increase incentives for the local administrations, an additional bonus was introduced in 2011 for each registered ghost building. See also Decreto Legge 79/2010, art. 10, 11.
} 


\section{Tax Enforcement and Retrospective Voting: Con- ceptual Frameworks}

This section presents several conceptual frameworks that rationalize the impact of a change in tax enforcement on voters' electoral choices. Through verbal presentation of these models, we show that the program can affect voter behavior through its impact on tax enforcement by changing the voter inference about the politician type and by reducing uncertainty about it. We also highlight the role of voters' information in shaping the electoral response. Analytical details are provided in the Theory Appendix.

The frameworks are based on the modeling of retrospective voting [Barro, 1973; Ferejohn, 1986] and tax evasion [Allingham and Sandmo, 1972]. The main intuition of retrospective voting models is that citizens decide whether to reelect the incumbent based on their welfare in the most recent political term. ${ }^{13}$ The various conceptual frameworks share several features. In all the models we adopt a standard probabilistic voting approach [Lindbeck and Weibull, 1987]. Voters are heterogeneous in their ability to evade. This ability could be a function of the psychological and physical costs of evading. We consider a simple case with two fixed types of voters: evaders and non-evaders. Evaders pay taxes only if enforcement occurs, while non-evaders always pay taxes. Enforcement depends both on the politician (type and effort) and on a noise. Voters do not observe the two components and are uncertain over the politician type, as in Banks and Sundaram [1998]. They use previous realizations to form expectations about the politician, in the spirit of Holmstrom [1982].

Voters derive utility from disposable income and from the overall level of enforcement, for instance, through the increased provision of public goods and deficit reduction. This implies that enforcement has two effects on evaders' utility, which go in opposite directions. First, enforcement decreases the disposable income for evaders. Second, cracking down on tax evasion increases the size of the government, which benefits all citizens, including evaders. Non-evaders also obtain an additional non-monetary benefit from enforcement. One example is the case where, because of fairness concerns, non-evaders derive direct utility from the enforcement of evaders' tax payments, independent of their monetary returns. ${ }^{14}$ As a result of these channels, an increase in enforcement will have an ambiguous impact on voter welfare and

\footnotetext{
${ }^{13}$ For empirical applications based on the retrospective voting model framework see: Brender [2003]; Besley and Pratt [2006]; Brender and Drazen [2008]; Ferraz and Finan [2008]; Alesina, Carloni, and Lecce [2012]; Nannicini, Stella, Tabellini and Troiano [2013]; Drago, Nannicini and Sobbrio [2014].

${ }^{14}$ For experimental evidence on this channel, see Carpenter et al. [2009]; Casari and Luini [2009]; Ouss and Peysakhovich [2012].
} 
voting behavior. In addition, the net benefits of an increase in government will intuitively be larger when government efficiency in public good provision and the intensity of non-monetary benefits from the additional enforcement are higher.

We now turn to the specific features of each framework. In the first conceptual framework, the Ghost Buildings program is modeled as a positive shock to enforcement. Voters observe the increase in building registrations but have limited information about the specific "production function" of enforcement (i.e., information collected by the central government, the efforts of local administrations, and complementarity between the two sources). This in turn increases the belief they hold about the enforcement propensity of the local incumbent type. Models with rational but poorly informed voters have received growing attention in the literature [Wolfers, 2009; Cole, Healy, and Werker, 2013; Manacorda, Miguel, and Vigorito, 2011; Pande, 2011]. Poor voter information is particularly relevant for the Ghost Buildings program. It was likely difficult for voters to make inferences about who exactly was ramping up enforcement. Local administrations' efforts complemented the initial identification process. In addition, evidence from media reports and town bulletins suggest that mayors often took credit for the enforcement following the program, and in some cases, even for the initial stages of building identification through aerial pictures. ${ }^{15}$ Consistent with the logic described in the previous paragraph, the change in beliefs about the incumbent enforcement type generates an ambiguous effect on her reelection likelihood, heterogeneous in government efficiency and in the non-monetary benefits from enforcement for non-evaders.

In the second conceptual framework, which is heavily based on the model of political agency in Besley [2007], the Ghost Buildings program reduces the cost of enforcement for the local incumbent. Unlike the previous model, voters have perfect information about this change. In this model, politicians have heterogeneous preferences over enforcement. Enforcement is costly for politicians, and politicians gain an ego-rent from re-election. The cost reduction caused by the program can enable more pro-enforcement types (i.e., those who derive direct utility from increasing enforcement) to reveal their type through their now cheaper enforcement choice. The effect of an average increase in the enforcement level under the incumbent has again ambiguous predictions on election outcomes. The heterogeneities described above continue to hold.

Finally, in the third framework, we model the Ghost Buildings program as a change that, while leaving unchanged the average beliefs voters hold about the incumbent, reduces their dispersion. The main intuition is that the program allows the incumbent mayor to

\footnotetext{
${ }^{15}$ Some examples include Barca [2008], Bernardini [2011], Cavallaro [2011], Corriere della Città [2012], Dell'Oste and Trovati [2011], Gazzetta del Mezzogiorno [2012].
} 
better reveal their true type, as mayors who are in office when the program starts have the opportunity to be observed both in the state of the world with the program and in the one without the program. In the presence of voters with risk-averse preferences, this will lead to an increase in reelection rates. In addition, under standard additional assumptions, it is possible to derive again the heterogeneities by government efficiency and by the level of nonmonetary benefits non-evaders obtain from enforcement. In the empirical analysis, we do not aim at differentiating these models. Rather, the fact that all of the frameworks predict an ambiguous electoral effect of the program shows how uncovering the electoral consequences of the program is an empirical question, which does not depend on the specific modeling assumptions.

\section{Data and Descriptive Evidence}

\subsection{Data}

The main database for the analysis includes information on the number of parcels containing ghost buildings in each town. The aerial photographs detected more than two million such parcels. We target the population of 7,720 of the 8,092 Italian towns for which we can define the measure of ghost building intensity. Additionally, we obtain data on registered ghost buildings by the deadline of April 30, 2011. These allow us to define the ghost building registration rate as the percentage of ghost building parcels that were registered by the April 2011 deadline. To analyze the electoral response to ghost building registration, we also construct a measure of registration imputable to the incumbent administration. Specifically, we multiply the registration rate by the ratio between a) the time elapsed between program start date and election date and b) the time elapsed between program start date and April 2011.

We complement this information with data from the Italian Department of the Interior (Ministero degli Interni) on the universe of municipal elections from 1993 to 2011. In Figure I, we plot the number of elections per year. Towns vote in different years according to predetermined waves. We distinguish between elections before and after the beginning of the Ghost Buildings program. There are almost 5,200 municipalities for which we have data on an election that occurred after program inception (approximately 67 percent of the total number of towns targeted by the program). Two institutional reforms that occurred in the time span of our sample were relevant. First, in 1993, the starting year for our election

sample, Italian municipal politics were overhauled: a new electoral law changed the mayoral 
electoral system from party to individual ballot. Municipalities below 15,000 inhabitants adopt a single round system, while a runoff system is in place above this threshold. ${ }^{16}$ The 1993 reform also introduced a two-term limit. Second, in 2000, the length of the mayoral term was extended from four to five years. ${ }^{17}$

In addition to the core data, we collect geographic and socio-economic data at the municipality level from the Italian National Statistical Office. Finally, we use two additional data sources to test the channels driving the electoral response: town-level government expenditures (from the Ministero degli Interni) and a region-level standardized score to the question "Do you justify tax cheating?" from the European Values Study for each of the 19 Italian regions included in the program. Table I presents summary statistics for the variables used in the paper. Panel A presents the main variables related to the Ghost Buildings program. Panels B and C include town-level geographical and socio-economic covariates, respectively. These are measured prior to the inception of the Ghost Buildings program, mostly in the 2001 Population Census. Panel D summarizes the characteristics of the mayor in office at the time of the program inception in a particular town. ${ }^{18}$ In Panel E, we summarize the local election panel variables. Appendix Tables A.1 and A.2 provide a detailed description of data sources and variable definitions.

\subsection{The Correlates of Tax Evasion}

We use data from the Ghost Buildings program to study the correlates of tax evasion at the town level. Figure II presents our measure of ghost building intensity across Italian towns. Notably, ghost buildings are more prevalent in Southern Italy, and less widespread in the North. ${ }^{19}$ Table II presents the correlates of ghost building intensity (per 1,000 land

\footnotetext{
${ }^{16}$ Bordignon, Nannicini, and Tabellini [2013] show that under runoff elections, the number of political candidates is larger, but the influence of extremist voters on equilibrium policy is smaller.

${ }^{17}$ In limited cases, the term can last less than is provided by the law and elections can take place earlier. Those limited cases include the resignation of the mayor, the resignation of the majority of the council or a no-confidence vote in the council. Early termination is relatively infrequent in Italian local politics. In the post-program period, only approximately 7 percent of the towns experience an early termination of the mayor's term and for only 2.5 percent of the towns is the difference between the natural expiration of the term and the actual expiration of the term larger than one year. Consistent with the previous points, we verify that our results are not affected when we drop the sample of towns with an election year in the post-program period that is different from the one scheduled by the law.

${ }^{18}$ Only about half of mayors are matched to national parties, and the other parties are difficult to categorize within a left-right spectrum. We therefore choose not to focus on this variable in our analysis. We note that adding political party dummies to the controls in the regressions (for those mayors for which we have this information) does not affect the results we present later in the paper.

${ }^{19}$ The Agenzia del Territorio conducted its detection activities homogeneously throughout the country. Thus, heterogeneity in the number of detected unregistered buildings captures differences in actual levels
} 
registry parcels). In Column (1), we first study whether geographical factors (altitude, area of the town, number of land registry parcels) are correlated with tax evasion. In Column (2), we add socio-economic controls (population, income per capita, social capital, number of firms, urbanization rate). Finally, in Column (3), we show that our results are unaffected by the inclusion of regional fixed effects. ${ }^{20}$

We find that several geographic characteristics are strongly associated with tax evasion. In particular, controlling for other variables, tax evasion is higher in geographically larger municipalities. Plausibly, in cities with wide geographical extension, there are greater opportunities to hide unregistered buildings as the enforcement of building registration is more difficult and resource-intensive. However, we cannot decisively interpret this evidence as causal. Previous literature has shown, for example, that borders are endogenously determined (see, e.g., Alesina and Spolaore [1997], Alesina, Baqir and Hoxby [2004], Alesina, Easterly, and Matuszeski [2011]). Finally, as expected, tax evasion is negatively associated with both social capital and income. In particular, the finding on social capital is consistent with Putnam [2001], who finds that the percentage of tax evasion, as measured by the Internal Revenue Service, is strongly related to differences in social capital at the state level.

\subsection{The Ghost Building Registration Outcomes}

In this section, we provide details on the wave of registration of ghost buildings induced by the program. Administrative data reveal that 40 percent of the ghost buildings were registered by the end of 2011. The Agenzia del Territorio estimates that in 2011 total tax revenues increased by 472 million euros as a result of the program [Agenzia del Territorio and Dipartmento delle Finanze, 2012]. ${ }^{21}$

Local administrations receive a large share of the additional tax revenues generated by the program, and we estimate that approximately 65 percent of those revenues are generated by local taxes. We then run a back-of-the-envelope calculation using figures on the number of land parcels with ghost buildings, the registration rates, and the total additional tax revenues from the program. A one standard deviation increase in ghost buildings targeted by the program will increase local tax revenues by approximately 3 percent of the median

of non-registration at the time of the aerial photographing, as opposed to differential intensity in detection activity.

${ }^{20}$ For 3.5 percent of the towns in our sample we are missing at least one town-level control. In our regressions throughout the paper, for each control we include a binary indicator which is equal to one if the control is missing. In addition, we replace missing values with an arbitrary unique value.

${ }^{21}$ This figure does not include payments for overdue taxes from previous years. 
value. Using the same information, we calculate that, on average, the owner of a registered ghost building will face an additional yearly tax burden of approximately 528 Euros.

In section 6.2, when discussing the potential channels driving an electoral response, we also document that the program had a commensurate impact on local government expenditures. A potential additional margin of adjustment in response to the higher level of compliance could potentially be a reduction in tax rates. However, we note that tax rates exhibit very little variation after the program, mainly because of a law that introduced tax rate freezes (Legge 22 Dicembre 2008, n. 203). Specifically, we find that only 1 percent of the Italian towns move the property tax rate in any given year after 2008 and around 0.5 percent of towns move the municipal income tax rate in the same period. Consistent with this explanation, we do not find evidence of responses of tax rates to the program.

We then look at the ghost building registration rate. Figure III documents substantial dispersion across towns: the coefficient of variation in the registration rates takes a high value of $0.75 .^{22}$ Table III documents the impact of the characteristics of the mayor at the time of the program inception on this outcome. For a given level of the other covariates, the registration rate is higher when mayors are male, younger, more educated, or were born in the same city in which they serve as mayor. The correlation between gender and policies in Italian municipality is broadly consistent with the results of Gagliarducci and Paserman [2012], who find that female policymakers usually face greater difficulty in implementing policies while in office. To the extent that education can be considered a proxy for politicians' quality (see, for example, Besley, Montalvo and Reynal-Querol [2011]), this set of results also supports the view that better policymakers fight tax evasion more. We highlight the correlation between the mayor's birthplace and tax evasion enforcement. One possible explanation is that mayors born in the city care more about their birthplace, for instance because relatives and friends could be harmed by low resources available to the municipality. Another one could be that they have access to additional information that can facilitate tax evasion enforcement.

We acknowledge that this evidence relies on cross-sectional correlation analysis and thus should be interpreted with caution. However, we also notice that the results are robust to the inclusion of geographical controls, in Column (2) and then to the further inclusion of socioeconomic controls, in Column (3). With these caveats in mind, the findings of this section suggest that the mayors' characteristics did have a role in shaping registration activities across towns.

Finally, we show that the number of ghost buildings detected by the program is a good

\footnotetext{
${ }^{22}$ In 5.8 percent of the towns with a positive number of ghost buildings, none of the detected ghost buildings was registered by April 2011.
} 
predictor of the number of ghost buildings that were registered in response to the policy. Figure IV displays the relationship between the number of land parcels with ghost buildings eventually registered by the April 2011 deadline and the number of parcels that were identified as containing ghost buildings, both as a share of the total number of land registry parcels. In the graph, the $\mathrm{x}$-axis variable is partitioned into percentiles. The scatter plot shows a clear increasing relationship. In a linear regression analysis, an increase of one standard deviation in the detected intensity of ghost buildings raises the intensity of registered ghost buildings at April 2011 by approximately 0.75 standard deviations $(p<0.01)$. To summarize, the program scope at the town-level strongly predicts the program actual impact on tax enforcement. This

premise motivates the strategy that we adopt to estimate the impact of the Ghost Buildings program on electoral outcomes, which we introduce in the next section.

\section{Empirical Strategy}

\subsection{The Electoral Response to the Ghost Buildings Program}

In this section, we outline our approach to estimate the voter response to the Ghost Buildings program. Our empirical strategy exploits variation across towns in the program scope to increase tax enforcement. We implement a difference-in-differences approach based on town-level ghost building intensity.

In Section 4.3, we documented that mayors' characteristics, such as age, education, and gender, predict the registration rate of the detected ghost buildings. However, the actual levels of registration could depend on voter preferences and responsiveness to the program. Thus, a naive analysis examining the relationship between actual ghost building registrations and reelection outcomes will suffer from standard omitted variable bias. This motivates our focus on ex ante program scope to measure the impact of enforcement.

The rationale for our identification approach is that the program scope at the town level predicts the exogenous increase in enforcement induced by the Ghost Buildings program, as shown in Figure IV. Towns with a higher share of parcels containing detected ghost buildings also have, on average, a higher share of parcels with registered ghost buildings, as measured in April 2011. In a recent contribution, Mian and Sufi [2012] adopted a similar empirical approach to study the effects of the fiscal stimulus in the United States.

Importantly the intensity of ghost buildings is not a valid instrument for actual registration intensity. The program can affect incumbent reelection probability through other channels besides registration. For instance, it may give mayors an opportunity to extract 
rents from low program enforcement or by providing voters with information regarding past enforcement. In section 6.3, we discuss these alternative interpretations and show that they cannot drive our results. However, it could still be the case that these alternative mechanisms partially affected the voter response, which would violate the standard exclusion restriction required for an instrumental variable approach. ${ }^{23}$

Our baseline specification is therefore:

$$
R_{\text {imet }}=\beta_{0}+\beta_{1} \text { Post }_{i e} \cdot \text { Ghost Building Intensity } i+\eta_{m} \cdot \text { Post }_{i e}+\phi_{i}+\phi_{t}+\epsilon_{i m e t}
$$

The dependent variable $R_{\text {imet }}$ is a dummy that indicates whether the incumbent of town $i$ in macro-area $m$ is re-elected in election $e$ in year $t .{ }^{24}$ Observations where the incumbent cannot be reelected because of a binding term limit are excluded from the regression sample. The dummy Post is equal to one when election $e$ occurs after the beginning of the Ghost Buildings program in the town. The coefficients $\eta_{m}$ capture post-program period fixed effects that are specific to the four Italian macro-areas $m$ where town $i$ is located. ${ }^{25}$ We also include town fixed effects, $\phi_{i}$, and election year fixed effects, $\phi_{t}$. Town fixed effects would capture any timeinvariant difference across cities that may be correlated with ghost building intensity. Finally,

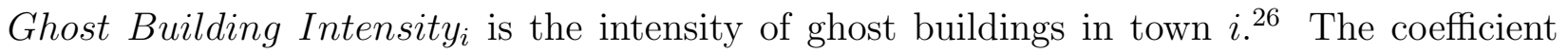
of interest, $\beta_{1}$, thus captures the differential impact of the Ghost Buildings program on incumbent reelection by ghost building intensity. Throughout the paper, we cluster standard errors at the provincial level to allow for spatial correlation in the error term. It should also be noted that, because of the existence of a two-term limit, our identification relies on mayors in their first term.

We adopt a similar regression model to study the impact of the program on other electoral competitiveness outcomes. We focus on four variables: i) the number of candidates running for mayor; ii) a binary indicator equal to one if the incumbent runs for election a second time; iii) the difference in the percentage of votes between the first and the second candidate; and iv) a binary indicator equal to one if a runoff takes place, which occurs in towns with

\footnotetext{
${ }^{23}$ As a check, we confirm that, in our prefereed specification (Table IV, Column (7)), the coefficient on the share of parcels with registered ghost buildings out of the total number of parcels when instrumented by ghost building intensity is 6.21 , significant at the 1 percent level.

${ }^{24}$ The variable equals zero both if a mayor eligible for reelection does not run again or if she runs again and is not elected.

${ }^{25}$ Macro-areas are North, Center, South, Islands.

${ }^{26}$ Given that booms and busts vary over time, they are not captured by town fixed effects, and they may be omitted from the model. We verify that all of our results are robust when we control for economic growth. Results are available upon request.
} 
more than 15,000 inhabitants when none of the candidates obtain an absolute majority in the first-round. ${ }^{27}$

One potential challenge to our identification strategy may arise from the town-specific timing of publications of the unauthorized buildings lists. On the one hand, if local administrators had influence over publication dates, unpopular mayors in cities with high evasion rates might lobby to delay publication. On the other hand, the central government might push to start the program earlier in those towns with a lower level of tax enforcement. In both these cases, our estimates of the impact of the Ghost Buildings program on reelection likelihood may capture a selection effect. We address this concern in several ways. First, as discussed in Section 2, we note that the timing of the publication was primarily determined at the provincial level by the availability of digital land registry maps and was highly clustered by province. ${ }^{28}$ Only approximately 7 percent of the post-program elections have values for the post-program indicator different from the one they would have had based on the modal date of publication in the province. ${ }^{29}$

To address these discrepancies, we implement an instrumental variable approach. We code elections based on whether they occur before or after the modal date of publication of the unauthorized building lists in the province. We then instrument the actual Post dummy with this binary indicator at the provincial level. The rationale for this choice is that the provincial level modal inception year may be correlated with historic characteristics of towns in the province (captured by our town fixed effects), but is unlikely to be driven by specific mayor characteristics. On the other hand, these may be driving the discrepancies between the town and the provincial program inception year. We adopt this strategy for our main specifications. ${ }^{30}$ In addition, in Appendix Table A.4, we present robustness checks using alternative instruments for the post-program indicator using the regional and national modal program inception years. The results are robust to these checks. ${ }^{31}$

\footnotetext{
${ }^{27}$ For the analysis of the difference in percentage votes between the first and second candidate, we always use first-round results, even for elections when a runoff occurs.

${ }^{28}$ Appendix Figure A.2 emphasizes the high level of provincial clustering in the publication years.

${ }^{29}$ It should also be noted that election times are not clustered at the provincial level and therefore there is a great deal of variation in election years across towns in the same province. We conduct an ANOVA analysis of elections dates in the last five years of the data (since towns vote every five years). We find that less than 9 percent of the variance is explained by the provincial fixed effects.

${ }^{30}$ The towns targeted by the program belonged to 101 provinces.

${ }^{31}$ We also note that our identification does not rely on comparison across towns with different publication years. In addition, we perform two additional checks related to the timing of program inception. First, we control for the interaction between the program inception year and the post program variable. Second, we check that there is no evidence of differential pre-trends in prior reelection rates across towns with different program inception years. Results are available on request.
} 
As is standard in difference-in-differences estimation, the identification of the coefficient of interest relies on two assumptions. The first is the absence of contemporary events that differentially affected towns with a higher ghost building intensity. We are not aware of other policies targeting this form of tax evasion that occurred concurrently with the Ghost Buildings program. However, it is still possible that other events, which differ in intensity by other variables correlated with ghost building intensity, occurred at the same time. We address this concern by presenting alternative specifications where we include interactions between a comprehensive set of geographical, socio-economic, and political controls, all measured before the beginning of the program, and the post-program binary indicator. The second assumption is the presence of parallel trends in the outcome variable. We assess this assumption using several tests and placebo exercises.

\subsection{Tax Enforcement and Heterogeneity Analysis}

The reduced form approach presented thus far tests whether a higher program scope to increase tax enforcement at the town level affects incumbent reelection likelihood in the postprogram period. We complement this baseline regression with further analysis to understand the channels behind this impact. First, we show that it is the tax enforcement induced by the program that drives the electoral response, as opposed to other potential mechanisms. For this purpose, we use actual ghost building registration data. In Section 4, we emphasized several important measurement limitations of these data that warrant caution. With these caveats in mind, we test whether, for a given intensity of ghost buildings, a higher ghost building registration rate induced by the program has a positive effect on incumbent reelection likelihood:

$$
\begin{aligned}
& R_{\text {imet }}=\gamma_{0}+\gamma_{1} \text { Post }_{i e} \cdot \text { Ghost Building Intensity } \text { I }_{i} \\
& +\gamma_{2} \text { Post }_{i e} \cdot \text { Registration Rate }_{i}+\zeta_{m} \cdot \text { Post }_{i e}+\mu_{i}+\mu_{t}+v_{\text {imet }}
\end{aligned}
$$

As discussed above, an obvious threat to the identification of $\gamma_{2}$ in Equation 2 arises from the fact that the registration effort is potentially correlated with many town-level confounders. We first check the robustness of the results to the inclusion of town and mayoral controls. In addition, the timing of the program provides a strategy that can alleviate this concern. Even if the program began in the same year in most of the towns, we can exploit the variation generated by the fact that Italian municipalities hold elections in different years. A longer time period between the beginning of the program and the election date naturally leads to 
more registration activities. This generates variation across towns in the registration rate achieved prior to the local election date that is plausibly uncorrelated with mayor quality. We use this instrumental variable strategy to examine the impact of a change in the registration rate on incumbent reelection likelihood. ${ }^{32}$

Second, we shed light on the channels through which the program could affect voters' political preferences. Consistent with the theoretical framework, we investigate the interaction among the political returns from the enforcement policy, tax culture - the stigma associated with evading taxes - and local government efficiency in delivering public goods. We use data from the European Values Study, the European component of the World Values Survey, to study the role of tax culture. Specifically, we use the answers to the question: "Do you justify cheating on tax?" Slemrod [2003] uses a similar variable to study the relationship between tax culture and social capital. We are not aware of other variables that can plausibly capture tax culture available at the sub-national level in Italy. In this dataset, geographical identification of respondents is available only at the regional level (19 regions). We thus compute and standardize region-level means. The following regression model tests whether the electoral response to the Ghost Buildings program varies by tax evasion tolerance:

$$
\begin{aligned}
& R_{\text {imet }}=\delta_{0}+\delta_{1} \text { Post }_{i e} \cdot \text { Ghost Building Intensity }_{i}+\delta_{2} \text { Post }_{i e} \cdot \text { Tax Evasion Tolerance }_{i} \\
& +\delta_{3} \cdot \text { Post }_{i e} * G B_{i} \cdot \text { Tax Evasion Tolerance } i+\xi_{m} \cdot \text { Post }_{i e}+\lambda_{i}+\lambda_{t}+\nu_{\text {imet }},
\end{aligned}
$$

where $\delta_{3}$ is the coefficient of interest.

We use the speed of public good provision as a proxy for the quality of public good delivery at the municipal level. This indicator is measured as the ratio of paid outlays in the municipal financial report over the total outlays committed in the budget. The rationale is that the provision of public goods is more effective in places where the actual allocation delivered to citizens is closer to the amount allocated in the budget. This proxy has already been used to measure the quality of public goods delivery [Gagliarducci and Nannicini, 2013; Grembi, Nannicini and Troiano, 2014]. We are not aware of other proxies that can plausibly capture the efficiency of the universe of municipal governments in Italy. We compute the speed of public good provision as the average across two pre-treatment years. The regression model to capture heterogeneity by this variable is similar to the one presented in Equation 3. Finally, we also assess the impact of the program on town-level public expenditures. To test whether the program scope to increase tax enforcement affected these expenditures, we

\footnotetext{
${ }^{32}$ Consistent with the discussion in Section 5.1, we use the modal inception year at the provincial level to compute the instrument.
} 
adopt a specification similar to the one presented in Equation 1, using the natural logarithm of the local government expenditures as the dependent variable.

\section{Results}

\subsection{Baseline Results}

In this section, we investigate the electoral consequences of the Ghost Buildings program. Figure $\mathrm{V}$ provides a visual analysis of the relationship between ghost building intensity and changes in the incumbent reelection likelihood - our main outcome variable - after the beginning of the program. On the x-axis, the ghost building intensity is partitioned into percentiles. The scatterplot displays a clear increasing relationship. ${ }^{33}$

Table IV formalizes this analysis above and presents the results of the difference-indifferences estimation discussed in Section 5. Column (1) reports the basic OLS specification ("Reduced Form") using the provincial post-program indicator. The coefficient remains stable with the addition of town fixed effects (Column (2)) and election year fixed effects (Column (3)). Including a rich set of town-level covariates interacted with the post-program dummy does not change the results (Column (4)). ${ }^{34}$ Starting in Column (5), we instrument the post-program indicator with the provincial post-program indicator. The coefficient is stable across the different specifications. Again, the results are robust to the inclusion of year fixed effects, town fixed effects, and interaction among town controls and the post-program indicator, in Columns (6)-(8), respectively. ${ }^{35}$

In Column (7), the baseline specification for the rest of the analysis, the reported coefficient on the interaction between ghost building intensity and the post-program indicator is 1.042 , significant at 1 percent. This magnitude implies that a one standard deviation increase in the town-level program scope to increase enforcement, as measured by the ghost building intensity, raises the likelihood of the incumbent's reelection by approximately 2.2 percentage points in post-program elections, relative to pre-program ones (from a sample mean of 45.4 percent). A back-of-the-envelope calculation suggests that the effect of a one standard deviation increase in Ghost Buildings program scope on incumbent reelection probability is on the order of magnitude of 6 percent of the incumbency effect in U.S. House elections [Lee,

\footnotetext{
${ }^{33}$ Appendix Figure A.2 presents a placebo version of Figure V.

${ }^{34}$ Our results are similar when using natural logarithms instead of levels for some of the controls.

${ }^{35}$ Appendix Table A.3 presents several additional robustness checks. We show that the results are robust to the inclusion of additional town controls (interacted with the post-program indicator), trimming procedures, alternative sample definitions, and normalization measures.
} 
2008].

In Figure VI, we check whether towns with different levels of evasion were on different trends in the probability of incumbent reelection before the treatment. We report point estimates and confidence intervals on ghost building intensity for each of the elections preand post-program. The figure shows that, before the Ghost Buildings program started, the probability of reelection of the incumbent was independent of tax evasion. However, after the beginning of the program there is a statistically and economically significant impact. Thus, the coefficient pattern in Figure VI suggests that the common trend assumption holds in our setting. One potential concern is that because of the term limit rule, we only include towns with first-term mayors. However, if the results were purely explained by composition, one would expect large jumps in reelection rates even in pre-program elections. The lack of such cyclical changes in our pre-trends graph attenuates the concerns arising from the fact that the composition of towns change. Additionally, it is encouraging that our results in Table IV are robust to the inclusion of a rich set of controls interacted with the post-program dummy: if the sample composition were driving the observed effects, we would expect the inclusion of the town covariates to substantially reduce the estimates.

In addition, we conduct a placebo check based on the fact that the program was not implemented in the Trentino Alto-Adige region. We first impute the value of the ghost building intensity by using the results in Table II. We then perform a Triple Difference Estimator (DDD), where we augment our research design with the difference between the reelection rate of Trentino Alto-Adige before and after the treatment. The main coefficient of interest in this research design is statistically significant and statistically indistinguishable from our main effect. We report the results in Appendix Table A.6.

In Table $\mathrm{V}$, we study the impact of the program on other measures of election competitiveness, as described in Section 5, using a regression strategy analogous to Table IV. For each of these variables, we report the specifications used in Columns (7) and (8) of Table IV. An increase in ghost building intensity reduces the competitiveness of local elections. Specifically, a one standard deviation increase in ghost building intensity reduces the number of candidates by 1.8 percent of the sample mean. In addition, it increases the likelihood that the incumbent runs again by 4.1 percent, though this effect is smaller and no longer significant when including other controls (Column 4). A one standard-deviation increase in ghost building intensity also increases the margin of victory by 3.4 percent and reduces the likelihood of a runoff by 18 percent (this variable is only defined in towns with population 
above 15 thousands). ${ }^{36}$

The combination of the above results is consistent with the idea that both the incumbent mayor and other potential candidates correctly anticipate a stronger incumbent advantage as a result of the program. ${ }^{37}$ This in equilibrium shapes the actual election competiveness and the incumbent reelection prospects. ${ }^{38}$

\subsection{Tax Enforcement, Tax Culture and Efficiency of Local Gov- ernments}

This section elaborates on some of the potential channels through which the anti-evasion program could increase voter support for the incumbent. Table VI presents the results from the estimation of Equation 2. This step aims at showing that the increase in tax enforcement induced by the program - the ghost buildings registration - drove the electoral response.

In Column (1), we present the correlation between the ghost building registration rate and the likelihood of incumbent reelection. We find that, controlling for ghost building intensity, a one standard deviation increase in ghost building registration rate (0.18) raises reelection likelihood by 3.1 percentage points. In Column (2), we show that adding the interaction between town- and mayor-level controls and the post-program indicator does not change the results. In Column (3), we show that in a cross-city regression, the number of years elapsed from the program start date are a strong predictor of the city-level registration rate. This can be interpreted as a first stage for our instrumental variable approach.

In Columns (4) and (5), we use the years elapsed since the program start date as an instrument for the registration rate imputable to the incumbent administration. ${ }^{39}$ In the IV

\footnotetext{
${ }^{36}$ Appendix Figure A.4 shows that the parallel trend assumption also holds for the other political outcome variables described above.

${ }^{37}$ Following suggestions from two Referees, we also looked at voter turnout and found no significant impact of the program on this outcome variable.

${ }^{38}$ The set of our results thus implies that a share of the reelection effect can be explained by the (endogenous) decision to rerun. For instance, incumbents may be more likely to rerun given the increase in town revenues generated by both phases of the the program (i.e., before and after the April 2011 deadline). Since the choice to run is endogenous, the impact of the program on the likelihood of incumbent victory conditional on re-running is not easily identifiable. It should also be noted that the baseline means of the reelected and rerun variables are different, and that not every mayor that decides to rerun ends up winning the election. A simple back-of-the-envelope calculation, assuming that the probability of winning conditional on re-running for the incumbent is at the sample mean of 79.4 percent, suggests that at most 67 percent of our reelection effect can be explained by the re-running effect.

${ }^{39}$ In this IV specification we do not control for year fixed effects. Three quarters of the post-program elections come from cities that started the program in 2007. Thus, we lose statistical significance when running this specification, although it is reassuring that the coefficient of interest remains positive and large. Results are available upon request.
} 
specification, a one standard deviation increase in the registration rate raises the reelection likelihood by 11.3 percentage points in post-program elections. Finally, in Column (5) we show that the IV estimate is unchanged when adding the interaction between town-level controls and the post-program indicator. ${ }^{40}$ Even if our instrument is uncorrelated with any idiosyncratic city-specific characteristics, we are unable to rule out the possibility that having the program for longer time has an independent effect on its impact on the probability of reelection, which would invalidate the IV strategy. While we acknowledge this possibility, we still believe that our instrument performs well in addressing the main endogeneity concern for the registration efforts of the mayors (which may depend on the mayor's ability or incentives).

We then provide empirical evidence on the role of tax culture and local government efficiency in shaping the political returns to enforcement. Table VII presents the results from the estimation of Equation 3. The coefficient of interest, $\delta_{3}$, captures the impact on the electoral response to the program of a standard-deviation increase in the variables measuring either the tolerance for tax evasion or the municipal speed of public goods provision. In Column (1), we show that a one standard deviation increase in the score measuring tolerance for tax evasion reduces the point estimate of the impact of ghost buildings on reelection by .64 (significant at the ten percent level). Column (2) shows that the magnitude of the coefficient is stable, or if anything, increases (in absolute value) when adding the triple interactions with macro-area dummies. ${ }^{41}$

Turning to local government efficiency, in Column (3) we find that a one standard deviation increase in the speed of public good provision increases the point estimate of the impact of ghost buildings on reelection by 0.63 and that this coefficient is statistically significant at the ten percent level. We then confirm that this interaction effect does not simply capture geographical variation in the responsiveness across different parts of Italy by adding triple interactions across the post-program indicator, the ghost building intensity, and the macro area dummies. The sign and economic significance of the coefficient is robust (Column (4)), although estimated less precisely $(\mathrm{p}$-value $=.137)$. To summarize, while the limited power in these estimates should evoke some caution, the analysis presents evidence that voters' responses depend on underlying tax morale and government spending efficiency.

Finally, Table VIII presents the results of the estimation of the baseline regression model in Equation 1, using the log of town-level government expenditures. Column (1) presents the

\footnotetext{
${ }^{40}$ The results on the registration rate regressions are robust to the checks presented in Table A.3. Results are available upon request.

${ }^{41}$ Standard errors are similar when performing region-level cluster bootstrapping, following Cameron, Gelbach and Miller [2008].
} 
reduced-form results, using the post-program indicator based on the provincial mode. The point estimate is .436 (significant at 10 percent). The coefficient is stable when instrumenting the post-program indicator with the provincial one and is slightly larger when including interactions among town-level controls and the post-program indicator (Columns (2) and (3)). While the effect of the program is statistically significant, we also note that it is fairly small. A one standard-deviation increase in ghost-building intensity increases expenditures by approximately 1 percent. We believe that it is unlikely that this effect explains the entirety of the incumbent reelection effect we documented earlier in the paper. Consistent with the suggestive evidence provided by the heterogeneity in tax culture, we suggest that non-monetary factors (e.g., the direct utility non-evaders derive from catching the shirkers) must play an important role.

\subsection{Alternative Explanations}

Our results suggest that the increase in tax enforcement induced by the program drives the results on voting support for the local incumbents. In this section, we show that this channel more than offsets several alternative potential explanations about the impact of the Ghost Buildings program.

First, the publication of the number of ghost buildings could generate information about the incumbent. We believe this to be both unlikely and inconsistent with our findings. The number of ghost buildings is a slow moving stock variable that is likely to have accumulated over decades, rather than a reflection of only the most recent years. Most of the buildings found by the Agenzia del Territorio were not newly constructed. The existence of a term limit and the fact that the average time to complete a building in Italy is longer than most other OECD countries suggest that most of these buildings were built before the incumbent's election. Second, we note that voters who could potentially receive information from the publication are most likely the ones who were not evading before the program, as evaders were already aware of their own evasion.

Keeping this premise in mind, we believe our results rule out this alternative explanation. In one version of this alternative story, voters, after learning about low levels of evasion detected by the program, reward the current mayor for having properly enforced tax payment in the past. This hypothesis predicts a negative impact of the detected ghost building intensity on incumbent reelection in post-program elections, and as such it is obviously inconsistent with our baseline results.

In another version of this alternative explanation, voters reward an incumbent mayor 
for having allowed high levels of evasion in the past. First, this contradicts the intuition mentioned above that non-evaders, rather than those who previously evaded, are the ones who are potentially acquiring new information. Second, this is unlikely because the purpose of the program, and therefore the publication, was to shut down the evasion opportunity. Third, it is at odds with the fact that the positive impact of program intensity on incumbent reelection is lower in regions with higher tolerance for tax evasion. Fourth, it is also inconsistent with the result that towns with higher registration levels are more likely, rather than less likely, to reelect an incumbent mayor.

In a second potential alternative explanation, the program gives the incumbent an electoral rent by allowing her to not register the targeted ghost buildings, for instance, by reporting errors in the results generated by the mapping process. ${ }^{42}$ If this were the prevailing mechanism, we would expect the positive impact of the program to be stronger in regions with a higher tolerance for tax evasion, but we find the opposite to be the case. In addition, such an explanation is inconsistent with the result that a higher share of registered ghost buildings at the time of a local election increases the reelection likelihood.

Third, one concern is that mayors from towns with low ghost building intensity may step to higher level positions, as models of career concerns could predict. We note this is unlikely to generate the large results we find in our data since the level of these transitions is generally low. In addition, we collect data on the elected members of Provincial and Regional Councils and Italian and European Parliaments. We confirm that the Ghost Buildings program intensity does not affect significantly the likelihood that an incumbent mayor holds any of these seats within three years from the end of his appointment (Appendix Table A.5).

To summarize, the empirical results provide strong evidence that it is the additional tax enforcement induced by the program that drives the increase in the reelection prospects of the incumbent, as opposed to these alternative explanations.

\section{Conclusion}

A rapidly growing literature shows that interventions that improve the technology of tax enforcement - third-party reporting, cross-checking, or better auditing algorithms - can substantially reduce tax evasion. Yet, political incentives to adopt these technologies are also of crucial importance. Policymakers will delay or prevent enforcement policies if they are

\footnotetext{
${ }^{42}$ For example, the press agency of the mayor of a town in our sample, Capaccio Paestum, explicitly criticized the excessive media attention to the program, indicating that the unregistered buildings in that city were unregistered due to citizens' needs [Comune di Capaccio Paestum, 2010.]
} 
bound to lose support because of them. In spite of this, little is known about the electoral impact of fighting tax evasion. This paper provides evidence of a positive interaction between technological improvements in tax-payer monitoring and political incentives. Specifically, local incumbents obtain positive political returns - an increase in their reelection likelihood - from the Ghost Buildings program, a nationwide anti-evasion policy in Italy that was based on a novel enforcement technology.

The underlying tax culture, broadly defined as the individual propensity and social norms determining evasion for a given level of technology, is another important determinant of tax compliance. It shapes the enforcement level a government can achieve for a given enforcement technology. We show that tax culture affects the political returns to undertaking anti-evasion policies. The increase in incumbent reelection probabilities in response to the Ghost Buildings program is larger in areas with a lower self-reported tolerance for tax evasion. Finally, we document that the political returns to enforcement policies are higher when the government is more efficient in providing public goods.

These findings have two important policy implications. First, they provide a framework for thinking about the political feasibility of policies that increase the visibility of tax evasion, thus lowering monitoring costs and increasing policymakers' incentives to improve enforcement. This has immediate relevance for special interest politics. Concentrated evader groups might effectively lobby to keep evasion hidden from the public, but they are unlikely to be able to punish an incumbent who enforces tax compliance after the evasion becomes broadly visible.

Second, there is potential complementarity among anti-evasion policies, government responsiveness, and social preferences for tax compliance. Governments that plan to implement novel enforcement policies should concurrently attempt to strengthen their capabilities, for instance, by improving the speed at which they respond to citizen's needs, or by increasing the social stigma associated with tax evasion. This complementarity will likely increase the returns politicians obtain from anti-evasion policies and will thus make such policies better aligned with political agents' incentives.

We are aware that using an identification strategy based on a specific natural experiment enhances the internal validity of our study but may come at the price of lower external validity, concerning other countries or other taxes. Yet, we speculate that evidence of positive political returns to anti-evasion policies in Italy, a country often cited as an example of poor tax culture, could be a lower bound for other OECD countries. We believe an interesting goal for future work would be to elucidate the potential non-linearity in the relationship between 
the prevalence of tax evasion and political returns to enforcement policies. In addition, we believe that complementarity between enforcement policies and social norms on evasion could potentially be relevant for policy design in other regions of the world.

Another important dimension of external validity concerns enforcement policies targeting other types of evasion. One of the merits of the Ghost Buildings program is that it detected the entire stock of evasion. In contrast, the effectiveness of policies targeting other taxconcealing activities might vary according to the ability of the specific evader to hide, which might, in turn, affect how the public would respond. We hope future work will shed light on the political returns to other enforcement policies around the world.

STANFORD UNIVERSITY

UNIVERSITY OF MICHIGAN AND NBER 


\section{References}

Agenzia del Territorio and Dipartimento delle Finanze, "Regolarizzazione degli Immobili Fantasma." Comunicato Stampa Congiunto, 2012

Alesina, Alberto. "Credibility and Policy Convergence in a Two-Party System with Rational Voters." American Economic Review, 78 (1988), 796-806.

Alesina, Alberto, Reza Baqir and Caroline Hoxby. "Political jurisdictions in heterogeneous communities." The Journal of Political Economy, 112(2) (1988), 348-396.

Alesina, Alberto, Dorian Carloni, and Giampaolo Lecce, "The Electoral Consequence of Large Fiscal Adjustments," Fiscal Policy after the Financial Crisis. University of Chicago Press, 2012. 531-570.

Alesina, Alberto, William Easterly, and Janina Matuszeski. "Artificial States." Journal of the European Economic Association 9.2 (2011): 246-277..

Alesina, Alberto, and Enrico Spolaore. "On the Number and Size of Nations." The Quarterly Journal of Economics 112.4 (1997): 1027-1056.

Allingham, Michael G., and Agnar Sandmo. "Income Tax Evasion: A Theoretical Analysis." Journal of Public Economics 1 (1972), 323-338.

Alm, James, Betty R. Jackson, and Michael McKee. "Estimating the Determinants of Taxpayer Compliance with Experimental Data." National Tax Journal (1992): 107-114.

Almunia, Miguel, and David Lopez Rodriguez. "Heterogeneous Responses to Effective Tax Enforcement: Evidence from Spanish Firms." (2014).

Andreoni, James, Brian Erard, and Jonathan Feinstein. "Tax compliance." Journal of Economic Literature (1998): 818-860.

Aparicio, Gabriela. "Monitoring and its Interaction with Punishment in Tax Enforcement: Evidence from a Regression Discontinuity Design." Georgetown University, working paper (2012)

Artavanis, Nikolaos T., Adair Morse, and Margarita Tsoutsoura. "Tax Evasion across Industries: Soft Credit Evidence from Greece." Chicago Booth Research Paper 12-25 (2012).

Banks, Jeffrey S., and Rangarajan K. Sundaram. "Optimal Retention in Agency Problems." Journal of Economic Theory 82.2 (1998): 293-323. 
Barca, Matteo. "I primi cittadini della montagna commentano i dati apparsi sul sito dell'Agenzia del territorio sugli immobili non denunciati." L'Informazione Provincia Montagna, March 21st (2008).

Barro, Robert J. "The Control of Politicians: an Economic Model." Public Choice 14.1 (1973): 19-42.

Bernardini, Daniele. "Il Comune va a caccia delle case fantasma." La Nazione, March 18th (2011).

Besley, Timothy. "Principled Agents?: The Political Economy of Good Government." OUP Catalogue (2007).

Besley, Timothy, and Stephen Coate. "An Economic Model of Representative Democracy." The Quarterly Journal of Economics (1997): 85-114.

Besley, Timothy, Jose G. Montalvo, and Marta Reynal-Querol. "Do Educated Leaders Matter?." The Economic Journal 121.554 (2011): F205-227.

Besley, Timothy, and Torsten Persson. "Taxation and Development." in Handbook of Public Economics Vol. 5, Alan J. Auerbach, Raj Chetty, Martin Feldstein, and Emmanuel Saez, eds. (2013).

Besley, Timothy, and Andrea Prat. "Handcuffs for the Grabbing Hand? Media Capture and Government Accountability." The American Economic Review 96.3 (2006): 720-736.

Bird, Richard M., and Eric M. Zolt. "Technology and Taxation in Developing Countries: From Hand to Mouse." National Tax Journal (2008): 791-821.

Bordignon, Massimo, Tommaso Nannicini, and Guido Tabellini. "Moderating Political Extremism: Single Round vs. Runoff Elections under Plurality Rule. IZA Discussion Paper 7561 (2013).

Brender, Adi. "The Effect of Fiscal Performance on Local Government Election Results in Israel: 19891998." Journal of Public Economics 87.9 (2003): 2187-2205.

Brender, Adi, and Allan Drazen. "How Do Budget Deficits and Economic Growth Affect Reelection Prospects? Evidence from a Large Panel of Countries." The American Economic Review (2008): 2203-2220.

Cameron, A. Colin, Jonah B. Gelbach, and Douglas L. Miller. "Bootstrap-based improvements for inference with clustered errors." The Review of Economics and Statistics 90.3 (2008): 414-427.

Cannari, Luigi, and Giovanni D'Alessio. "The Opinion of Italians on Tax Evasion." Bank of Italy Economic Research Paper 618 (2007). 
Carpenter, Jeffrey, Samuel Bowles, Herbert Gintis, and Sung-Ha Hwang. "Strong reciprocity and team production: Theory and evidence." Journal of Economic Behavior and Organization 71, no. 2 (2009): 221-232.

Carrillo, Paul, Dina Pomeranz, and Monica Singhal. "Dodging the Taxman: Firm Misreporting and Limits to Tax Enforcement" No. w20624. National Bureau of Economic Research, 2014.

Casari, Marco, and Luigi Luini. "Group Cooperation under Alternative Punishment Institutions: An Experiment." Journal of Economic Behavior and Organization, 71(2) (2009): $273-282$.

Cavallaro, Francesco. "Sindaci Pronti alla Lotta all'Evasione." Il Sole 24 Ore. February 16th (2011).

Chetty, Raj, John N. Friedman, and Emmanuel Saez. "Using Differences in Knowledge across Neighborhoods to Uncover the Impacts of the EITC on Earnings." American Economic Review 103.7 (2013): 2683-2721.

Cole, Shawn, Andrew Healy, and Eric Werker. "Do Voters Demand Responsive Governments? Evidence from Indian Disaster Relief." Journal of Development Economics 97.2 (2012): 167-181.

Comune di Capaccio Paestum. "Comunicato Stampa, n. 134/10", July 29th (2010).

Corriere della Città. "Crisi? Parla il sindaco De Fusco." March 28th (2012).

DellOste, Cristiano, and Gianni Trovati. "Il Tesoro delle Case Fantasma." Il Sole 24 Ore (2011).

Drago, Francesco, Tommaso Nannicini, and Francesco Sobbrio. "Meet the Press: how Voters and Politicians Respond to Newspaper Entry and Exit." American Economic Journal: Applied Economics 6.3 (2014): 159-188.

Ferejohn, John. "Incumbent Performance and Electoral Control." Public Choice 50.1 (1986): $5-25$.

Ferraz, Claudio, and Frederico Finan. "Exposing Corrupt Politicians: The Effects of Brazil's Publicly Released Audits on Electoral Outcomes." Quarterly Journal of Economics 123.2 (2008):703-745

Gagliarducci, Stefano, and M. Daniele Paserman. "Gender interactions within hierarchies: evidence from the political arena." The Review of Economic Studies (2011): 1021-1052.

Gagliarducci, Stefano, and Tommaso Nannicini. "Do Better Paid Politicians Perform Better? Disentangling Incentives from Selection." Journal of the European Economic Association 11.2 (2013): 369-398. 
Gazzetta del Mezzogiorno. "Caccia Aperta ai Furbetti Proprietari di Case-Fantasma. Il Comune Vuole Censire quelle Abitazioni che Sfuggono alle Tasse." January 11th (2012).

Gordon, Roger, and Wei Li. "Tax Structures in Developing Countries: Many Puzzles and a Possible Explanation." Journal of Public Economics 93.7 (2009): 855-866.

Grembi, Veronica, Tommaso Nannicini, and Ugo Troiano. "Policy Responses to Fiscal Restraints: A Difference-in-Discontinuities Design." (2014).

Hallsworth, Michael, John A. List, Robert D.Metcalfe, and Ivo Vlaev. "The behavioralist as tax collector: Using natural field experiments to enhance tax compliance" National Bureau of Economic Research, working paper no. 20007. (2014).

Holmstrom, Bengt. "Managerial incentive problems: A dynamic perspective." In Essays in Economics and Management in Honor of Lars Wahlbeck. Helsinki: Swedish School of Economics. (1982); reprinted in Review of Economic Studies 66 (1999): 169-182.

Kleven, Henrik, Martin Knudsen, Claus Kreiner, Soren Pedersen, and Emmanuel Saez. "Unwilling or Unable to Cheat? Evidence from a Randomized Tax Audit Experiment in Denmark." Econometrica, 79(3). (2011): 651-692.

Kumler, Todd, Eric Verhoogen and Judith Frías. "Enlisting Workers in Monitoring Firms:Payroll Tax Compliance in Mexico." Working paper. (2001).

La Porta, Rafael, and Andrei Shleifer. "The Unofficial Economy and Economic Development." Brookings Papers on Economic Activity, 47, no. 1 (2008): 123-135.

Langellotti, Maria Brigida. "Lotta all'evasione, il Comune scopre 200 case fantasma." La Nazione, 11th April (2014).

Lee, David. "Randomized experiments from non-random selection in U.S. House elections." Journal of Econometrics 142 (2008) 675697.

Lindbeck, Assar, and Jorgen Weibull.'Balanced-Budget Redistribution as the Outcome of Political Competition." Public Choice, 52 (1987): 273-297.

Luttmer, Erzo F.P, and Monica Singhal. "Tax Morale." Journal of Economic Perspectives, 28(4). (2014). 149-168.

Marino, Mariarosaria, and Roberta Zizza. "Personal Income Tax Evasion in Italy: An Estimate by Taxpayer Type." Chapters, in: Tax Evasion and the Shadow Economy, chapter 3 Edward Elgar. (2012).

Mian, Atif and Amir Sufi. "The Effects of Fiscal Stimulus: Evidence from the 2009 Cash for Clunkers Program." Quarterly Journal of Economics, 127(3), (2012): 1107-1142.

Manacorda, Marco, Edward Miguel and Andrea Vigorito "Government Transfers and Political Support." American Economic Journal: Applied Economics, 3(3). (2011). 
Nannicini, Tommaso, Andrea Stella, Guido Tabellini, and Ugo Troiano. "Social Capital and Political Accountability." American Economic Journal: Economic Policy, 5(2). (2013): $222-50$.

Naritomi, Joana. "Consumers as Tax Auditors." LSE working paper (2015).

Olson, Mancur. "The Logic of Collective Action: Public Goods and the Theory of Groups." Harvard University Press. (1965).

Ouss, Aurelie, and Alex Peysakhovich. "When Punishment Doesn't Pay: The 'Cold Glow' Heuristic and Decisions to Punish." Harvard University, working paper. (2012).

Pande, Rohini. "Can Informed Voters Enforce Better Governance? Experiments in LowIncome Democracies." Annual Review of Economics, Vol. 3 (2011): 215-237.

Perez-Truglia, Ricardo and Ugo Troiano. "Shaming Tax Delinquents: Theory and Evidence from a Field Experiment in the United States," NBER working paper. (2015).

Pomeranz, Dina. "No Taxation without Information: Deterrence and Self-Enforcement in the Value Added Tax." American Economic Review, forthcoming.

Putnam, Robert. "Social Capital: Measurement and Consequences." ISUMA - Canadian Journal of Policy Research, 2, 1, (2001): 41-51.

Rothstein, Bo. "Trust, Social Dilemmas and Collective Memories." Journal of Theoretical Politics, vol. 12,(2000): 477-501.

Saez, Emmanuel. "Do Taxpayers Bunch at Kink Points?" American Economic Journal: Economic Policy, 2, (2010): pp. 180-212.

Saiz, Albert. "The Geographic Determinants of Housing Supply." The Quarterly Journal of Economics, vol. 125(3).(2010): pages 1253-1296.

Slemrod, Joel. "Trust in Public Finance." In S. Cnossen and H.-W. Sinn (eds.) Public Finance and Public Policy in the New Century, 49-88. Cambridge, MA: MIT Press. (2003).

Slemrod, Joel. "Cheating Ourselves: The Economics of Tax Evasion." Journal of Economic Perspectives, 21(1) (2007): 25-48.

Slemrod, Joel, Marsha Blumenthal, and Charles Christian. "Taxpayer Response to an Increased Probability of Audit: Evidence from a Controlled Experiment in Minnesota." Journal of Public Economics 79(3) (2001): 455- 483.

Slemrod, Joel, and Shlomo Yitzhaki. "Tax avoidance, evasion, and administration." Handbook of Public Economics, in: Alan J. Auerbach and Martin Feldstein (ed.). Handbook of Public Economics, edition 1, volume 3, chapter 22, pages 1423-1470. (2002). 
Spicer, Michael W., and Lee A. Becker. "Fiscal Inequity and Tax Evasion: An Experimental Approach." National Tax Journal, June, 33(2) (1980):171-175.

Torgler, Benno. "Tax Morale, Rule-Governed Behaviour, and Trust." Constitutional Political Economy, June, 14(2) (2003): 119-140.

Torgler, Benno.Tax Morale and Tax Compliance: A Theoretical and Empirical Analysis, Cheltenham U.K.: Edward Elgar. (2007)

Tullock, Gordon. "Some problems of majority voting." Journal of Political Economy, 67 (1959): 571-579.

Wolfers, Justin. "Are Voters Rational? Evidence from Gubernatorial Elections." University of Pennsylvania, working paper. (2009)

Yang, Dean. "Integrity for Hire: An Analysis of a Widespread Customs Reform." Journal of Law and economics, 51(1), (2008a): 25-58.

Yang, Dean. "Can enforcement backfire? Crime displacement in the context of customs reform in the Philippines," Review of Economics and Statistics 90 (2008b):1- 14 


\section{Tables}

Table I: Summary Statistics

\begin{tabular}{lccccc}
\hline \hline \multicolumn{1}{c}{ Variable } & Mean & Std. Dev. & Min. & Max. & N \\
\hline Panel A: Ghost Building Town Variables & & & & & \\
Ghost Building Intensity & 0.027 & 0.021 & 0 & 0.187 & 7720 \\
Registered Ghost Building Intensity (Apr 2011) & 0.006 & 0.006 & 0 & 0.051 & 7720 \\
Ghost Building Registration Rate (Apr 2011) & 0.243 & 0.181 & 0 & 1 & 7720 \\
Panel B: Geographic Town Variables & & & & & \\
Town Area Size (sq km) & 37.044 & 50.096 & 0.2 & 1307.71 & 7720 \\
Altitude (mt) & 510.584 & 461.487 & 0 & 3072.5 & 7720 \\
Land Registry Parcels (1,000) & 10.776 & 13.278 & 0.001 & 514.372 & 7720 \\
Panel C: Socio-Economic Town Variables & & & & & \\
Population (1,000) & 7.225 & 40.23 & 0.033 & 2546.804 & 7720 \\
Disposable Income per capita (1,000 Euros) & 13.449 & 3.042 & 5.013 & 44.949 & 7720 \\
Urbanization Index & 1.619 & 0.684 & 1 & 3 & 7720 \\
Non-Profit Associations/1,000 pop & 5.293 & 3.912 & 0.212 & 81.218 & 7720 \\
Number of Firms per capita & 0.076 & 0.027 & 0.018 & 0.344 & 7720 \\
Panel D: Mayor Variables & & & & & \\
Mayor Age & 49.03 & 9.5 & 21 & 83 & 7720 \\
Mayor Education & 3.29 & 0.69 & 1 & 5 & 7720 \\
Mayor Born Same City (0/1) & 0.47 & 0.49 & 0 & 1 & 7720 \\
Mayor Term Number & 1.3 & 0.46 & 1 & 2 & 7720 \\
Mayor Woman (0/1) & 0.1 & 0.3 & 0 & 1 & 7720 \\
Panel E: Election Panel Variables & & & & & \\
Term Limit Indicator (0/1) & 0.201 & 0.401 & 0 & 1 & 32422 \\
Post Program Election (0/1) & 0.143 & 0.351 & 0 & 1 & 25893 \\
Years Elapsed since Program Inception (=0 if $\leq 0)$ & 0.299 & 0.802 & 0 & 4 & 25893 \\
Incumbent Reelection (0/1) & 0.454 & 0.498 & 0 & 1 & 25893 \\
N. Candidates & 2.761 & 1.301 & 1 & 17 & 24585 \\
Incumbent Rerun (0/1) & 0.572 & 0.495 & 0 & 1 & 25525 \\
Victory Margin & 25.999 & 26.942 & 0 & 100 & 23933 \\
Runoff (0/1) & 0.525 & 0.499 & 0 & 1 & 2285 \\
\hline
\end{tabular}

Notes: Socio-Economic Town Variables are collected before the Ghost Buildings program inception. Mayor Variables refer to characteristics of the incumbent mayor at the time of program inception. Summary statistics for the Election Panel Variables are reported for the subsample of elections with no binding term limit, except for Term Limit Indicator. In all the tables, we replace missing values for the town-level controls with regional means, so to retain a constant sample size. The range of missing values across variables spans from 0 to $3.8 \%$. The results are unchanged if, for each covariate, we add a dummy equal to one for a missing value, instead. A detailed description and source of each variable is provided in Appendix Tables A.1 and A.2. 
Table II: The Determinants of Ghost Building Intensity (per 1,000 land parcels)

\begin{tabular}{lccc}
\hline \hline & $(1)$ & $(2)$ & $(3)$ \\
\hline Town Area Size (sq km) & $0.102^{* * *}$ & $0.123^{* * *}$ & $0.098^{* * *}$ \\
Altitude (mt) & $(0.021)$ & $(0.015)$ & $(0.012)$ \\
& $-0.015^{* * *}$ & $-0.009^{* * *}$ & $-0.011^{* * *}$ \\
Land Registry Parcels (1,000) & $(0.002)$ & $(0.002)$ & $(0.002)$ \\
& $-0.236^{* * *}$ & $-0.328^{* * *}$ & $-0.270^{* * *}$ \\
Population (1,000) & $(0.065)$ & $(0.070)$ & $(0.047)$ \\
& & 0.020 & 0.004 \\
Disposable Income per capita (1,000 Euros) & & $(0.016)$ & $(0.011)$ \\
& & $(0.363)$ & $-1.224^{* * *}$ \\
Urbanization Index & & $5.940^{* * *}$ & $4.404^{* * *}$ \\
& & $(1.837)$ & $(1.652)$ \\
Non-Profit Associations/1,000 pop & & $-0.463^{* * *}$ & $-0.207^{* * *}$ \\
Number of Firms per capita & & $(0.147)$ & $(0.074)$ \\
& & $\left(20.244^{* * *}\right.$ & $89.886^{* * *}$ \\
Region FE & & & $(17.828)$ \\
Observations & 7720 & 7720 & 7720 \\
\hline \hline
\end{tabular}

Notes: The dependent variable is the town-level ghost building intensity per thousand of parcels, defined as the ratio between the number of land registry parcels with ghost buildings and the total number of land registry parcels, multiplied by one thousand. The mean of the dependent variable is 26.69 . Standard errors are clustered at provincial level. ${ }^{*} \mathrm{p}<0.1,{ }^{*} \mathrm{p}<0.05,{ }^{* * *} \mathrm{p}<0.01$. 
Table III: The Determinants of the Ghost Building Registration Rate

\begin{tabular}{lccc}
\hline \hline & $(1)$ & $(2)$ & $(3)$ \\
\hline Mayor Age & $-0.066^{* * *}$ & $-0.067^{* * *}$ & $-0.054^{* * *}$ \\
& $(0.021)$ & $(0.021)$ & $(0.019)$ \\
Mayor Education & $0.802^{* * *}$ & $0.702^{* *}$ & $0.806^{* * *}$ \\
& $(0.286)$ & $(0.271)$ & $(0.239)$ \\
Mayor Born Same City $(0 / 1)$ & $1.054^{* *}$ & $1.128^{* * *}$ & $0.946^{* *}$ \\
& $(0.424)$ & $(0.425)$ & $(0.411)$ \\
Mayor Term Number & -0.201 & -0.083 & -0.082 \\
& $(0.355)$ & $(0.341)$ & $(0.351)$ \\
Mayor Woman (0/1) & -0.915 & $-1.223^{*}$ & $-1.185^{*}$ \\
& $(0.637)$ & $(0.625)$ & $(0.608)$ \\
\hline Geographic Controls & & $\mathrm{X}$ & $\mathrm{X}$ \\
Socio-Economic Controls & & & $\mathrm{X}$ \\
Observations & 7720 & 7720 & 7720 \\
\hline \hline
\end{tabular}

Notes: The dependent variable is the town-level ghost building registration rate (multiplied by 100), defined as the ratio between the number of land registry parcels with ghost buildings that get registered by April 2011 and the number of land registry parcels with ghost buildings identified at the beginning of the program, multiplied by 100 . The mean of the dependent variable is 24.32 . Refer to Table I for a description of the Geographic and Socio-Economic Controls. All the regressions include regional fixed effects and yearof-program-inception fixed effects. Standard errors are clustered at provincial level. ${ }^{*} \mathrm{p}<0.1,{ }^{*} \mathrm{p}<0.05$, $* * * \mathrm{p}<0.01$. 


\begin{tabular}{|c|c|c|c|c|c|c|c|c|}
\hline & \multicolumn{4}{|c|}{ Reduced Form } & \multicolumn{4}{|c|}{2 SLS } \\
\hline & (1) & (2) & (3) & (4) & (5) & (6) & (7) & $(8)$ \\
\hline Ghost Building Intensity*Post & & & & & $\begin{array}{c}1.097^{* * *} \\
(0.358)\end{array}$ & $\begin{array}{c}1.114^{* * *} \\
(0.373)\end{array}$ & $\begin{array}{c}1.042^{* * *} \\
(0.378)\end{array}$ & $\begin{array}{c}1.117^{* * *} \\
(0.376)\end{array}$ \\
\hline Ghost Building Intensity*Province Post & $\begin{array}{c}1.083^{* * *} \\
(0.343)\end{array}$ & $\begin{array}{c}1.061^{* * * *} \\
(0.358)\end{array}$ & $\begin{array}{c}0.953^{* * *} \\
(0.360)\end{array}$ & $\begin{array}{c}0.991^{* * *} \\
(0.359)\end{array}$ & & & & \\
\hline Town FE & & $\mathrm{X}$ & $\mathrm{X}$ & $\mathrm{X}$ & & $\mathrm{X}$ & $\mathrm{X}$ & $\mathrm{X}$ \\
\hline Election Year FE & & & $\mathrm{X}$ & $\mathrm{X}$ & & & $\mathrm{X}$ & $\mathrm{X}$ \\
\hline Town Controls*Post & & & & $\mathrm{X}$ & & & & $\mathrm{X}$ \\
\hline Observations & 25893 & 25893 & 25893 & 25893 & 25893 & 25893 & 25893 & 25893 \\
\hline
\end{tabular}

Notes: The dependent variable is a binary indicator equal to one if the incumbent mayor is reelected (mean 0.454). Post is a binary indicator equal to one if the election occurs after the Ghost Buildings program inception. Province Post is a binary indicator equal to one if the election occurs after the Ghost Buildings program modal inception year in the province. In the columns grouped under the header "2SLS", Post is instrumented with Post Province. Ghost Building Intensity is defined as the ratio between the number of land registry parcels with ghost buildings and the total number of land registry parcels. All the columns include an interaction between macro-areas fixed effects and either Province Post (Columns (1)-(4)) or Post (Columns (5)-(8)). Columns (1) and (5) include the Ghost Building Intensity level. Town Controls*Post include town-level controls interacted with the Post dummy. Refer to Table I for a list of these variables. The regression sample includes all the elections between 1993 and 2011 in which the incumbent does not face a binding term-limit. Standard errors are clustered at provincial level. ${ }^{*} \mathrm{p}<0.1,{ }^{* *} \mathrm{p}<0.05,{ }^{* * *} \mathrm{p}<0.01$. 
Table V: Ghost Building Intensity and Election Competitiveness

\begin{tabular}{|c|c|c|c|c|c|c|c|c|}
\hline & \multicolumn{2}{|c|}{ N. Candidates } & \multicolumn{2}{|c|}{ Incumbent Rerun } & \multicolumn{2}{|c|}{ Victory Margin } & \multicolumn{2}{|c|}{ Runoff } \\
\hline & $(1)$ & $(2)$ & $(3)$ & $(4)$ & $(5)$ & $(6)$ & $(7)$ & $(8)$ \\
\hline Ghost Building Intensity*Post Program & $\begin{array}{c}-2.383^{* *} \\
(1.057)\end{array}$ & $\begin{array}{c}-3.155^{* * *} \\
(1.152)\end{array}$ & $\begin{array}{l}1.115^{* *} \\
(0.457)\end{array}$ & $\begin{array}{c}0.610 \\
(0.437)\end{array}$ & $\begin{array}{c}42.063 \\
(25.984)\end{array}$ & $\begin{array}{l}41.882^{*} \\
(23.614)\end{array}$ & $\begin{array}{c}-4.502^{* * *} \\
(1.383)\end{array}$ & $\begin{array}{c}-4.271^{* * *} \\
(1.282)\end{array}$ \\
\hline Dependent Variable Mean & 2.761 & 2.761 & 0.572 & 0.572 & 25.999 & 25.999 & 0.525 & 0.525 \\
\hline Town Controls*Post & & $\mathrm{X}$ & & $\mathrm{X}$ & & $\mathrm{X}$ & & $\mathrm{X}$ \\
\hline Observations & 24441 & 24441 & 25483 & 25483 & 23562 & 23562 & 2216 & 2216 \\
\hline
\end{tabular}

Notes: N. Candidates is the number of candidates running for election. Incumbent Rerun is a binary indicator equal to one when the current incumbent runs for reelection. Victory Margin is the percentage point difference between the first and the second candidate in the elections (we use first-round percentages even for towns with a runoff). Runoff is a binary indicator, defined only for towns with more than 15,000 inhabitants, equal to one if the election requires a runoff. This occurs if the first candidate in the first round receives less than $50 \%$ of the votes. Post is a binary indicator equal to one if the election occurs after the Ghost Buildings program inception. In all the columns, Post is instrumented by Province Post, a binary indicator equal to one if the election occurs after the modal program inception year in the province. Ghost Building Intensity is defined as the ratio between the number of land registry parcels with ghost buildings and the total number of land registry parcels. All the regressions include town fixed effects, election-year fixed effects and an interaction between macro-areas fixed effects and Post. Town Controls*Post include town-level controls interacted with the Post dummy. Refer to Table I for a list of these variables. The regression sample includes all the elections between 1993 and 2011 in which the incumbent does not face a binding term-limit. Standard errors are clustered at provincial level. ${ }^{*} \mathrm{p}<0.1,{ }^{* *} \mathrm{p}<0.05,{ }^{* * *} \mathrm{p}<0.01$. 
Table VI: Ghost Building Registration and Incumbent Reelection

\begin{tabular}{lccccc}
\hline \hline & $(1)$ & $(2)$ & $(3)$ & $(4)$ & $(5)$ \\
& OLS & OLS & 1st Stage & 2SLS & 2SLS \\
\hline Ghost Building Registration Rate*Post & $0.173^{* *}$ & $0.147^{* *}$ & & $0.625^{* * *}$ & $0.656^{* * *}$ \\
& $(0.072)$ & $(0.069)$ & & $(0.196)$ & $(0.197)$ \\
Years Elapsed since Program Inception & & & $0.077^{* * *}$ & & \\
& & & $(0.009)$ & & \\
Ghost Building Intensity*Post & $1.276^{* * *}$ & $1.423^{* * *}$ & & $1.561^{* * *}$ & $1.904^{* * *}$ \\
& $(0.383)$ & $(0.408)$ & & $(0.391)$ & $(0.448)$ \\
\hline Town Controls*Post & \multicolumn{5}{c}{$\mathrm{X}$} \\
Observations & 25893 & 25893 & 7720 & 25893 & 25893 \\
\hline \hline
\end{tabular}

Notes: Columns (1), (2), (4), and (5) present election-panel regressions where the dependent variable is a binary indicator equal to one if the incumbent mayor is reelected (mean 0.454). Post is a binary indicator equal to one if the election occurs after the Ghost Buildings program inception. In all the columns, Post is instrumented by Province Post, a binary indicator equal to one if the election occurs after the modal program inception year in the province. Ghost Building Intensity is defined as the ratio between the number of land registry parcels with ghost buildings and the total number of land registry parcels. Registration Rate refers to the registration rate at April 2011 in columns (1) and (2) and to the instrumented imputed registration rate at the time of the election in columns (4) and (5). The regressions include town fixed effects, an interaction between macro-areas fixed effects and Post and, in the OLS specifications, year fixed effects. The regression sample for these columns includes all the elections between 1993 and 2011 in which the incumbent does not face a binding term-limit. Extra Controls*Post include town-level controls interacted with the Post dummy. Refer to Table I for a list of these variables.

Column (3), First Stage, presents cross-town regressions where the dependent variable is the ghost building registration rate at April 2011. The variable Years Elapsed since Program Inception measures the years elapsed between the program inception year and 2011. The regression includes the levels of the above controls, the level of the ghost building intensity and macro-areas fixed effects. Standard errors are clustered at provincial level. ${ }^{*} \mathrm{p}<0.1,{ }^{* *} \mathrm{p}<0.05,{ }^{* * *} \mathrm{p}<0.01$. 
Table VII: Ghost Building Intensity and Incumbent Reelection: Heterogeneity Analysis

\begin{tabular}{lcccc}
\hline \hline & $(1)$ & $(2)$ & $(3)$ & $(4)$ \\
\hline Ghost Building Intensity*Post & $1.063^{* * *}$ & $1.311^{* *}$ & $1.174^{* * *}$ & $1.229^{*}$ \\
& $(0.380)$ & $(0.668)$ & $(0.391)$ & $(0.682)$ \\
$\ldots *$ Justify Tax Cheating & $-0.639^{*}$ & $-0.734^{*}$ & & \\
& $(0.364)$ & $(0.404)$ & & \\
$\ldots *$ Speed of Public Good Provision & & & $0.627^{*}$ & 0.592 \\
& & & $(0.380)$ & $(0.397)$ \\
\hline GBI*Macro Area*Post & No & Yes & No & Yes \\
Observations & 25893 & 25893 & 25893 & 25893 \\
\hline \hline
\end{tabular}

Notes: The dependent variable is a binary indicator equal to one if the incumbent mayor is reelected (mean 0.454). Post is a binary indicator equal to one if the election occurs after the Ghost Buildings program inception. In all the columns, Post is instrumented by Province Post, a binary indicator equal to one if the election occurs after the modal program inception year in the province. Ghost Building Intensity is defined as the ratio between the number of land registry parcels with ghost buildings and the total number of land registry parcels. GBI*Macro Area*Post is the triple interaction among macro-areas fixed effect, ghost building intensity and Post. All the regressions include town fixed effects, election-year fixed effects, interactions between macro-areas fixed effects and Post, and an interaction between the relevant heterogeneity variable for the column and Post. The regression sample includes all the elections between 1993 and 2011 in which the incumbent does not face a binding term-limit. Standard errors are clustered at provincial level. ${ }^{*} \mathrm{p}<0.1,{ }^{* *} \mathrm{p}<0.05,{ }^{* * *} \mathrm{p}<0.01$. 
Table VIII: Local Government Expenditures

\begin{tabular}{|c|c|c|c|}
\hline & \multirow{2}{*}{$\frac{\text { OLS }}{(1)}$} & \multicolumn{2}{|c|}{ 2SLS } \\
\hline & & $(2)$ & $(3)$ \\
\hline Ghost Buildings Intensity ${ }^{*}$ Post & & $\begin{array}{c}0.497^{*} \\
(0.263)\end{array}$ & $\begin{array}{c}0.621^{* * *} \\
(0.206)\end{array}$ \\
\hline Ghost Building Intensity*Post Province & $\begin{array}{c}0.441^{*} \\
(0.253)\end{array}$ & & \\
\hline Extra Controls*Post & No & No & Yes \\
\hline Observations & 74664 & 74664 & 74664 \\
\hline
\end{tabular}

Notes: The dependent variable is the natural logarithm of municipal government expenditures. Post is a binary indicator equal to one if the election occurs after the Ghost Buildings program inception. In columns (2) and (3), Post is instrumented by Province Post, a binary indicator equal to one if the election occurs after the modal program inception year in the province. Ghost Building Intensity is defined as the ratio between the number of land registry parcels with ghost buildings and the total number of land registry parcels. Town Controls*Post include town level controls interacted with the Post dummy. Refer to Table I for a list of these variables. All the regressions include town fixed effects, election-year fixed effects and an interaction between macro-areas fixed effects and Post. Standard errors are clustered at provincial level. * $\mathrm{p}<0.1,{ }^{* *} \mathrm{p}<0.05,{ }^{* * *} \mathrm{p}<0.01$. 
Figures

Figure I: Number of Elections per Year

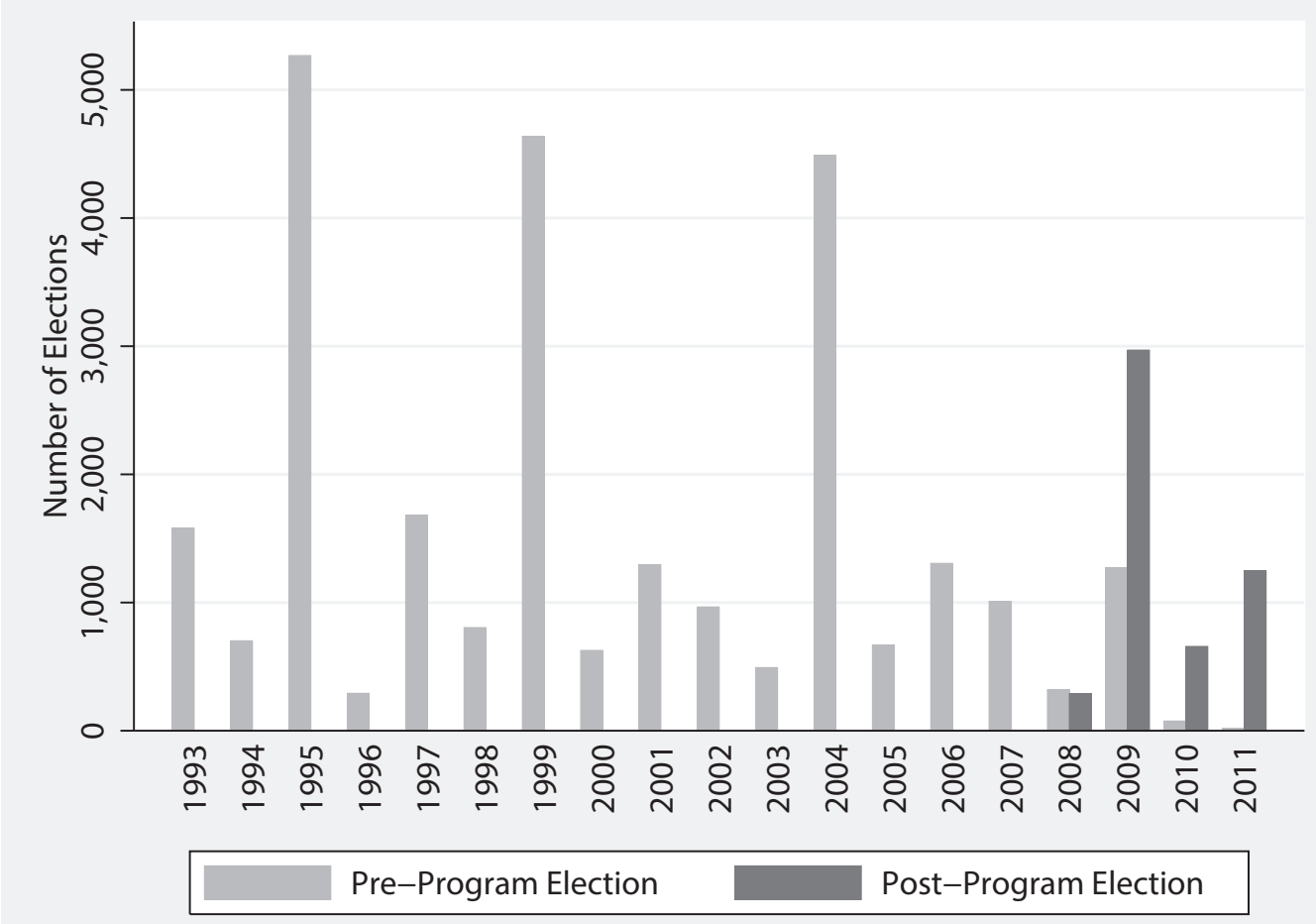

Notes: The figure shows, for each calendar year, the number of elections held before and after the inception of the Ghost Buildings program. 
Figure II: Ghost Building Intensity (per 1,000 land registry parcels)

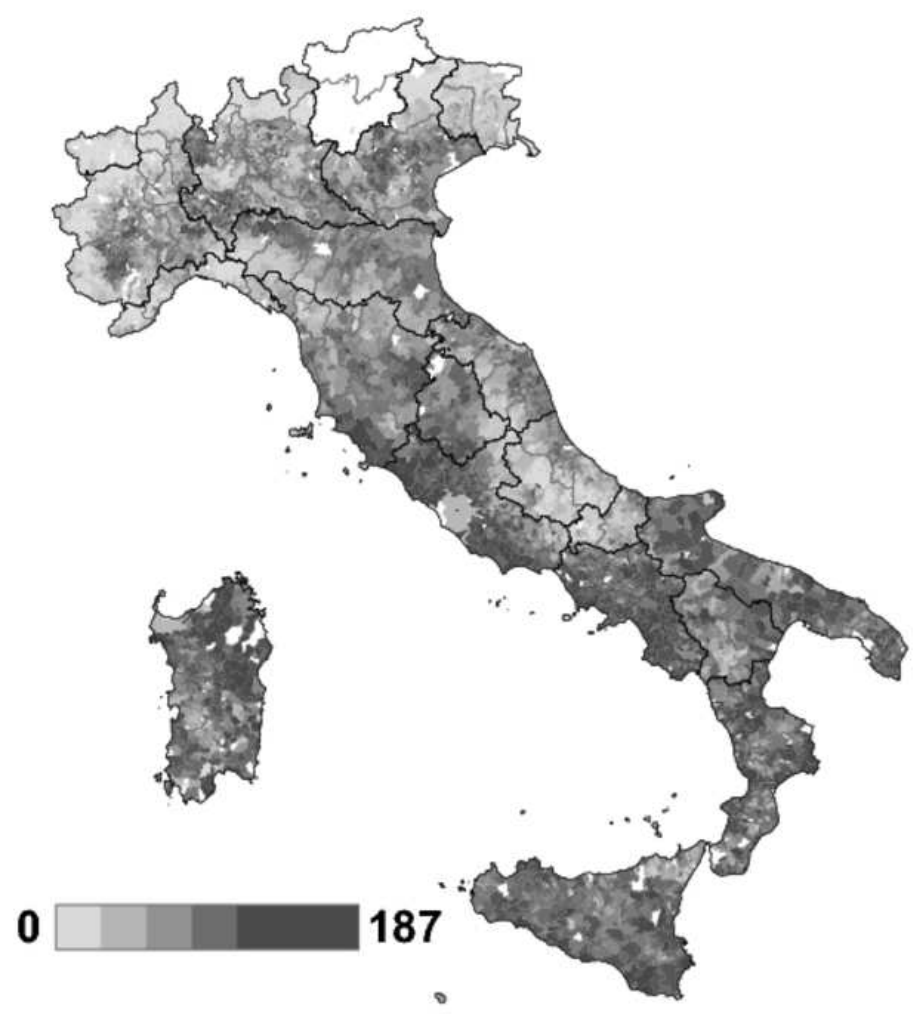

Notes: In this figure, Ghost Building Intensity is defined as the number of land registry parcels with ghost buildings per thousand of land registry parcels. White areas identify towns with missing data. 
Figure III: Ghost Building Registration Rate

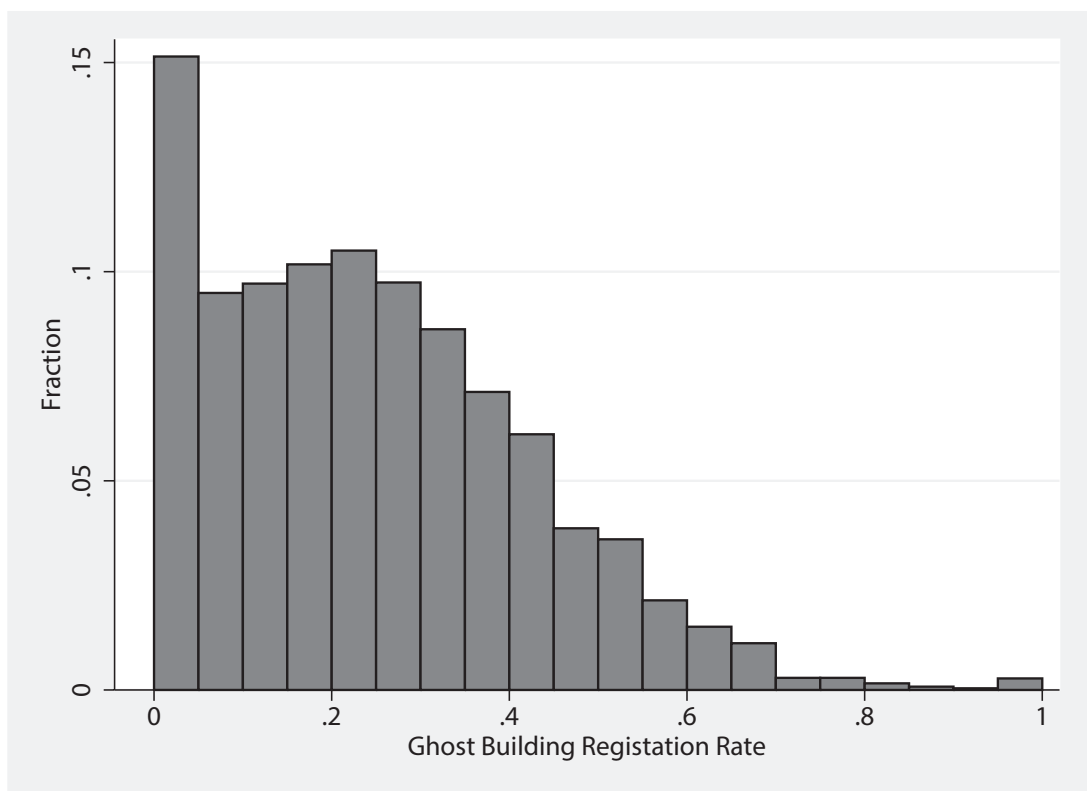

Notes: The histogram shows the distribution of the ghost building registration rate at April 30, 2011, defined as the ratio between the number of land registry parcels with ghost buildings that get registered by this date and the number of land registry parcels with ghost buildings identified by the program.

Figure IV: Registered Ghost Building Intensity

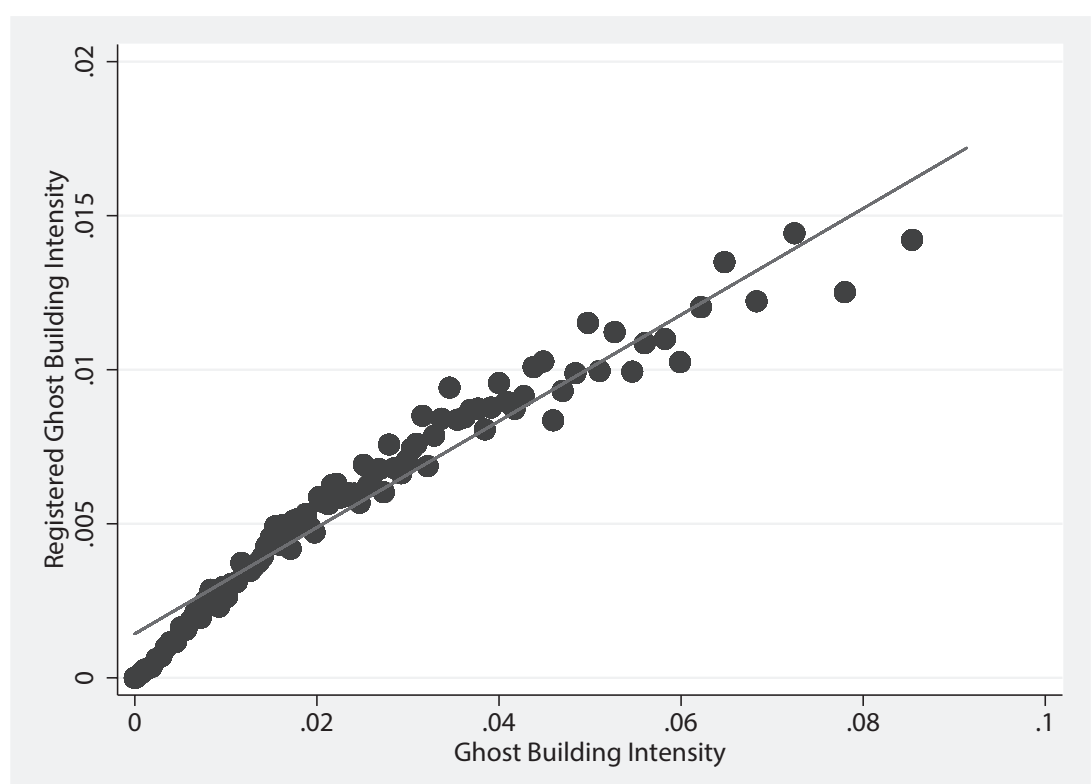

Notes: The scatter plots the relation between the fraction of land parcels with ghost buildings that get registered by April 2011 (Registered Ghost Building Intensity) and the fraction of land parcels with ghost buildings identified by the program (Ghost Building Intensity). The x-axis is partitioned into percentiles. The $\mathrm{x}$-axis of each dot is the median value of the ghost building intensity in the percentile. The $\mathrm{y}$-axis is the average value of the registered ghost building intensity in the percentile. We cut the top $1 \%$ of the $\mathrm{x}$-axis values from the graph. The line plots the predicted values from a linear regression model. 
Figure V: Difference in reelection rates pre- to post- Ghost Buildings program

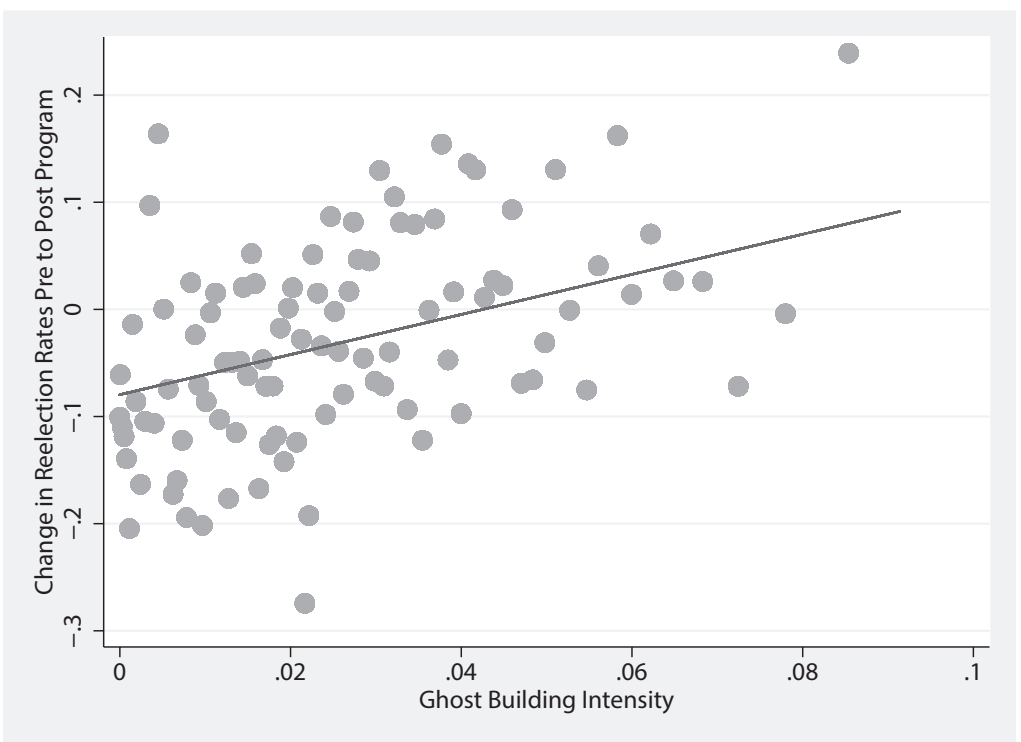

Notes: The scatter plots the relation between the change in the average (year-demeaned) reelection rate between the pre-program and the post-program periods and the Ghost Building Intensity. The x-axis is partitioned into percentiles. The $\mathrm{x}$-axis of each dot is the median value of the ghost building intensity in the percentile. The y-axis is the average value of the change in the reelection rate in the percentile. We cut the top $1 \%$ of the $\mathrm{x}$-axis values from the graph. The sample includes elections in which the incumbent does not face a binding term-limit. The line plots the predicted values from a linear regression model.

Figure VI: Ghost Building Intensity Coefficient by Election Pre/Post Program

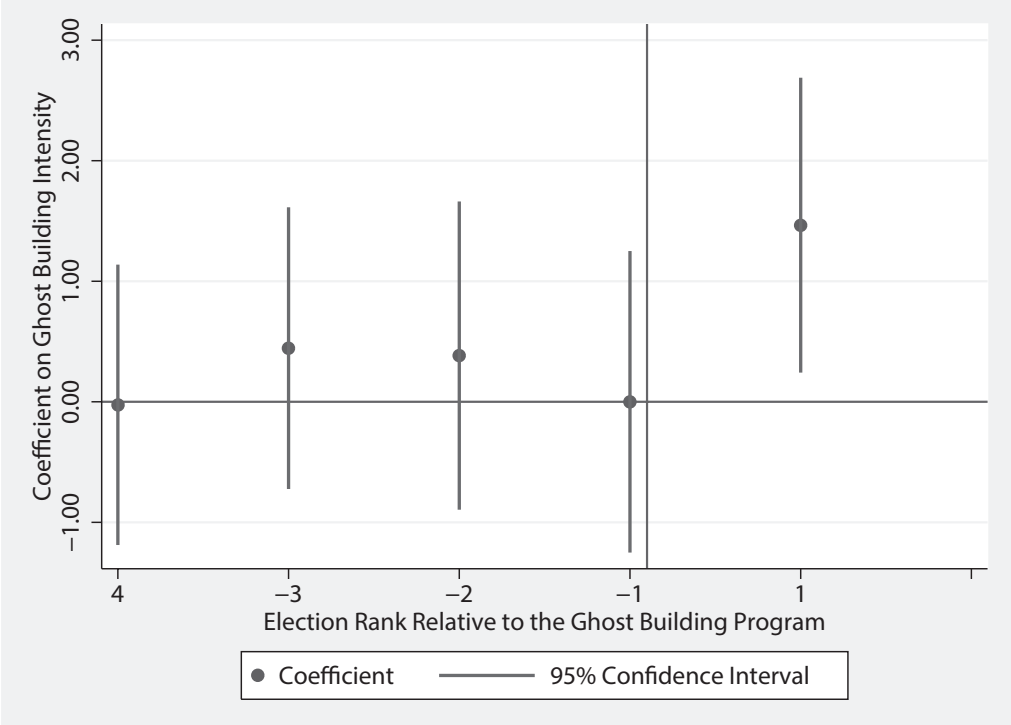

Notes: The graph reports the coefficients on the ghost building intensity for each election before and after the beginning of the Ghost Buildings program. On the x-axis, elections are ranked based on their occurrence relative to the program. The regression includes town and year fixed effects. The sample includes elections in which the incumbent does not face a binding term-limit. For each election rank, we report the point estimate and the $95 \%$ confidence interval. The election before the program ("-1") is the omitted category, for which confidence interval is obtained as the mean of the confidence interval width in election -2 and election +1 . The modal number of years between elections is five years between 1993 and 2001, and four afterwards. 